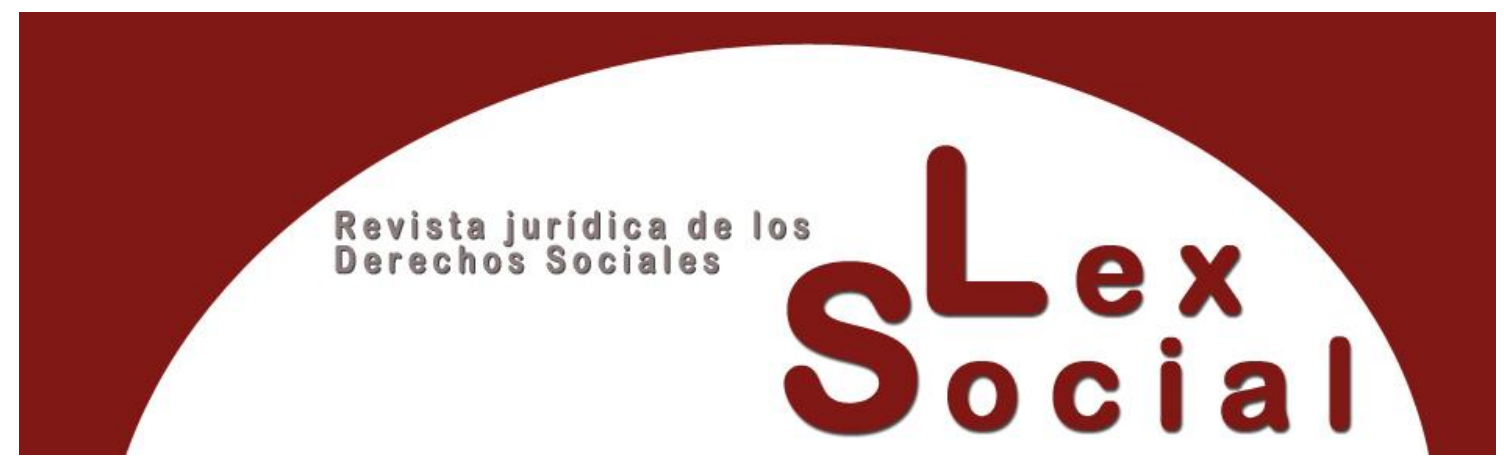

\title{
EVOLUCIÓN DE LA RESPONSABILIDAD DEL EMPRESARIO EN MATERIA DE ACCIDENTES DE TRABAJO EN EL ORDENAMIENTO JURÍDICO ESPAÑOL
}

\section{EVOLUTION OF THE RESPONSIBILITY OF THE ENTREPRENEUR IN THE FIELD OF WORK ACCIDENTS IN THE SPANISH LEGAL SYSTEM}

Dra. ANA NIEVES ESCRIBÁ PÉREZ

Profesora de Derecho del Trabajo y de la Seguridad Social Universidad Internacional de Valencia. https://orcid.org/0000-0003-2174-3594

Cómo citar este trabajo: Escribá Pérez, A.I. (2021). Evolución de la responsabilidad del empresario en materia de accidentes de trabajo en el ordenamiento jurídico español. Lex Social: Revista De Derechos Sociales, 11 (1), 378-409. https://doi.org/10.46661/lexsocial.5416

\section{RESUMEN}

La responsabilidad en materia de accidentes de trabajo ha sufrido cambios importantes, como no podía ser de otro modo, en el último siglo. La evolución ha sido significativa desde la aprobación de la primera Ley de Accidentes de Trabajo, en 1900, hasta la actualidad; desde la responsabilidad inicial basada en los contratos amparados en el ordenamiento civil hasta la triple responsabilidad que hoy en día se establece en el ordenamiento laboral -administrativa, civil y penal- pasando por la creación del contrato de trabajo como tal dentro del ámbito de las relaciones laborales hasta el recargo en las prestaciones de la seguridad social. Hoy en día es impensable una sociedad no comprometida con la seguridad y salud de sus trabajadores si bien es cierto que siguen existiendo. La finalidad de la responsabilidad empresarial debe traducirse en la búsqueda de la protección de las personas en el ámbito del derecho del trabajo.

Palabras Clave: accidentes de trabajo, prevención de riesgos laborales, responsabilidad civil, responsabilidad penal, responsabilidad administrativa.

\section{(c) ) EY-NC-SA}




\begin{abstract}
Responsibility for workplace accidents has undergone major changes, as it could not be otherwise, in the last century. The evolution has been important since the approval of the first Work Accident Law, in 1900, until today; from the initial responsibility based on the contracts covered by the civil order to the triple responsibility that is established today in the labor order -administrative, civil and criminal-, through the creation of the employment contract as such within the scope of relations work up to the surcharge on social security benefits. Today, a society that is not committed to the safety and health of its workers is unthinkable, although it is true that they continue to exist. The purpose of corporate responsibility must be translated into the search for the protection of persons in the field of labor law.
\end{abstract}

KEYWORDS: work accidents, prevention of occupational risks, civil responsibility, criminal responsibility, administrative responsibility.

\title{
SUMARIO
}

\section{Introducción}

II. Antecedentes históricos

1. Las teorías de la responsabilidad antes de la Ley de Accidentes de Trabajo

2. La responsabilidad del patrono por riesgo objetivo

III. El novedoso concepto de la responsabilidad patronal en la Ley de accidentes de trabajo de 1900: Su construcción jurídica

1. Introducción

2. La responsabilidad del patrono en materia en materia de accidentes de trabajo tras la aprobación de la Ley de Accidentes de Trabajo de 1900: La responsabilidad patronal por riesgo industrial

3. La Ley de Accidentes de Trabajo: El seguro de accidentes de trabajo

IV. La responsabilidad del empleador desde 1922 hasta 1995

1. La Ley de accidentes de trabajo de 1922

2. La Ley Bases de 1932

3. Decreto de 22 de junio de 1956 por el que se aprueba el Texto Refundido de la Legislación de Accidentes de Trabajo

4. Ley De Bases de la Seguridad Social de 28 de diciembre de 1963

5. Ley de Seguridad Social de 21 de abril de 1966

6. Ley General de la Seguridad Social de 30 de mayo de 1974

7. Real Decreto Legislativo 1/1994, de 20 de junio de 1994

$V$. La responsabilidad del empresario en materia de accidentes de trabajo en la actualidad 


\section{Introducción}

2. La responsabilidad civil

3. La responsabilidad penal

4. La responsabilidad administrativa

5. Los recargos en las prestaciones de la seguridad social

VI. Bibliografía.

\section{INTRODUCCIÓN}

El 30 de enero de 1900 se promulga la Ley de Accidentes de Trabajo ${ }^{1}$-en adelante LAT $^{2}$ ; con ella se puede decir que comienza el periodo de previsión social, es decir, el conjunto de medidas institucionales compuestas por seguros sociales de diferente índole e independientes entre sî́. Hasta la aprobación de la citada Ley las situaciones de necesidad de los obreros eran paliadas por las obras caritativas de los patronos -si así lo consideraban oportuno-, si bien es cierto que no tenían obligación alguna al respecto ${ }^{4}$. En aquella época era habitual que los operarios que habían sufrido daños o, en su caso, las personas de él dependientes, pudiesen interponer demanda de indemnización en el orden civil y que se condenara al patrono por delito, culpa o negligencia situación que avanzará con la aprobación de la LAT que configuró el concepto de accidente de trabajo -y su responsabilidad- por primera vez y que reguló el derecho del obrero a percibir indemnización en caso de sufrir accidente de trabajo para paliar las consecuencias de las lesiones causadas por el mismo.

La LAT supuso un antes y un después en la historia de la legislación en materia de derechos sociales en España y el enlace entre la fase de emergencia y la fase de crecimiento y consolidación ${ }^{5}$ del Derecho del Trabajo y la previsión social.

\section{ANTECEDENTES HISTÓRICOS}

La LAT reguló la responsabilidad objetiva del patrono frente a los accidentes de trabajo. La llegada de la Revolución Industrial a España y, por ende, la aplicación de las nuevas formas de trabajo que implicaban el uso de máquinas suponía un mayor número de riesgos en la realización del trabajo y, en consecuencia, un mayor número de accidentes. Cuando los operarios afectados por este tipo de situaciones se encontraban desprotegidos legalmente lo que suponía que, en la mayoría de los casos, pasaran a subsistir en

\footnotetext{
${ }^{1}$ Sancionada el 28 de julio de 1900 y publicada en la Gaceta de Madrid el 30 de julio del mismo año siendo Reina Regente María Cristina.

2 También conocida como Ley Dafo por ser Ministro de Gobernación, en aquel momento, Eduardo Dafo.

${ }^{3}$ ALONSO OLEA, Manuel. Instituciones de seguridad social, Madrid, Civitas, 9ª Edición, 1983, p. 22.

${ }^{4}$ GARCÍA GONZÁLEZ, Guillermo. Los inicios de la previsión social en España: responsabilidad patronal y seguro de accidentes en la ley de accidentes del trabajo de 1900. Lex Social: Revista de Derechos Sociales, 5(2), 2015, pp. 1-32.

${ }^{5}$ MARTÍN VALVERDE, Antonio. La formación del derecho del trabajo en España. La legislación social en la historia de España, de la revolución liberal a 1936. Congreso de los Diputados, 1987.
} 
condiciones infrahumanas por lo que surgió la preocupación ante dichas situaciones. Esta preocupación supuso que, finalmente, se regulara la responsabilidad de los patronos en esta materia y se materializara con la aprobación de la LAT para lo que fue necesario estar a lo dispuesto en la doctrina de la responsabilidad objetiva entendiendo que la protección económica del obrero suponía ${ }^{6}$, sin lugar a dudas, "uno de los gastos de la producción, a cargo, naturalmente, del empresario o patrono ${ }^{7}$ ".

\section{Las teorías de la responsabilidad antes de la Ley de Accidentes de Trabajo.}

Como ya he apuntado, hasta la aprobación de la LAT no existía en España regulación que permitiera gestionar la responsabilidad del patrono en materia de accidentes de trabajo. Con anterioridad a 1900 existían varias teorías para tratar las situaciones de incapacidad o fallecimiento a causa de los accidentes de trabajo; entre todas ellas cabe destacar la teoría de la culpa extracontractual que implicaba que tanto el patrono ${ }^{8}$ como el obrero eran responsables de forma recíproca siempre y cuando existiese culpa o negligencia ${ }^{9}$-si bien es cierto que en ese momento quedaban excluidos los casos en los que no mediara ninguna de las dos causas y, en este sentido, hay que resaltar que esto ocurría en la mayoría de los casos-.

En la España del siglo XIX era sumamente complicado justificar la responsabilidad del patrono en materia de accidentes de trabajo y este aspecto se hace latente si tenemos en cuenta que únicamente existe un fallo del Tribunal Supremo ${ }^{10}$-en adelante TS- que reconoce la responsabilidad de un patrono a favor de los familiares de un obrero que perdió la vida en un accidente de trabajo por falta de las medidas de seguridad necesarias ${ }^{11}$.

Otra de las teorías utilizadas ${ }^{12}$ en materia de responsabilidad por accidentes de trabajo en España antes de la aprobación de la LAT fue la teoría de la falta contractual que otorgaba un punto de vista innovador y establecía instrumentos necesarios para subsanar las situaciones de necesidad generadas a operarios -o dependientes-, en caso de que fuesen víctimas de un accidente de trabajo; en este sentido, los accidentes de trabajo se producían

\footnotetext{
${ }^{6}$ GARCÍA GONZÁLEZ, Guillermo. Los inicios de la previsión social en España: responsabilidad patronal y seguro de accidentes en la ley de accidentes del trabajo de 1900. Lex Social: Revista de Derechos Sociales, 5(2), 2015, pp. 1-32.

${ }^{7}$ GARCÍA ORMAECHEA, Rafael. Jurisprudencia del Tribunal Supremo y de la Comisión Superior de Previsión sobre Accidentes de Trabajo: 1902-1934, Madrid, Suc. de M. Minuesa de los Ríos, 1935, pp. 78.

${ }^{8}$ Hay que resaltar que era prácticamente imposible para los obreros probar la culpa o negligencia de los patronos por lo que, en la mayoría de los casos, no percibían la indemnización correspondiente -que resultaba obligatorio según el artículo 190 del Código Civil-. La dificultad venía, además, derivada del talante clasista y conservador de los jueces y porque estos suponían que siempre venía causada por una desgracia por lo que no contemplaban el factor culpa (Navarro Fernández, J. A., y Pertíñez Vílchez, F. (2002). Responsabilidad civil empresarial y riesgos laborales. Barcelona. Bosch, p. 22)

${ }^{9}$ GARCÍA GONZÁLEZ, Guillermo. Los inicios de la previsión social en España: responsabilidad patronal y seguro de accidentes en la ley de accidentes del trabajo de 1900. Op. Cit., pp. 1-32.

${ }^{10}$ De 14 de diciembre de 1894.

${ }^{11}$ GARCÍA GONZÁLEZ, Guillermo. Los inicios de la previsión social en España: responsabilidad patronal y seguro de accidentes en la ley de accidentes del trabajo de 1900. Op. Cit., pp. 1-32.

${ }^{12}$ Existían otras como la Teoría del Caso Fortuito o la Teoría del Ahorro.
} 
en el ámbito de un contrato de arrendamiento de servicios ${ }^{13}$ celebrado entre patrono y obrero y, por ende, el patrono se veía obligado a resarcir los daños producidos con objeto del mismo -además, durante ese mismo periodo, el patrono debía garantizar la seguridad del operario- ${ }^{14}$.

Esta última teoría tenía grandes fallos que debían ser rectificados; se le concedía al operario la misma categoría jurídica que a un objeto arrendado y, además, este tenía una importante carga procesal para poder, así, demostrar la culpa del patrono ${ }^{15}$. Dentro de las teorías elaboradas a este respecto cabe destacar -tal y como apunta el Doctor Guillermo García González- la que se basaba en la presunción de negligencia patronal o en la inversión de la carga de la prueba ${ }^{16} \mathrm{y}$, para ello, se invertía la prueba y era el empresario quien debía demostrar que no había existido negligencia ni culpa por su parte ${ }^{17}$.

\section{La responsabilidad del patrono por riego objetivo.}

Con la introducción de las nuevas tecnologías ${ }^{18}$ de la época, a finales del siglo XIX, se produjo un cambio significativo en el modo de producir, la industria dio un giro importante a su estilo de trabajo y ello supuso que hubo que adecuar el trabajo a la introducción de las máquinas en los procesos de producción. Este escenario era nuevo tanto para operarios como para patronos y permitía un aumento en la rapidez de los trabajos pero también supuso un aumento proporcional de los accidentes de trabajo que se originaban y, por ende, en la gravedad de los mismos. El derecho del trabajo de aquel momento no estaba preparado para un cambio tan brusco y, por tanto, las leyes no estaban adecuadas a los nuevos modelos de producción ${ }^{19}$.

En materia de accidentes de trabajo supuso que los obreros no tenían un sistema de protección social al que ampararse y, por lo tanto, tanto ellos como sus dependientes quedaban descubiertos en caso de que se viesen afectados por un accidente de trabajo.

Visto que los ordenamientos jurídicos de la época eran incapaces de poner remedio a la vertiente social derivada de los accidentes de trabajo se comenzó a trabajar en ello y, finalmente, se optó por dar una solución doctrinal al problema ${ }^{20}$; dicha solución consistía

\footnotetext{
${ }^{13}$ SILVESTRE, Javier. y PONS, Jerònia. El seguro de accidentes del trabajo, 1900-1935. En XVI Encuentro de Economía Pública: 5 y 6 de febrero de 2009: Palacio de Congresos de Granada. 2009. Pp. 123 y ss.

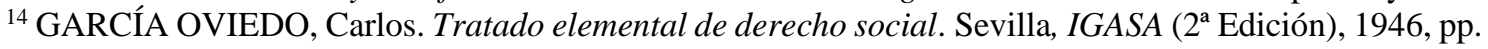
331.

${ }^{15}$ GARCÍA GONZÁLEZ, Guillermo. Los inicios de la previsión social en España: responsabilidad patronal y seguro de accidentes en la ley de accidentes del trabajo de 1900. Op. Cit., pp. 1-32.

${ }^{16}$ Según la que se entendía directamente que había habido negligencia del empresario en todo accidente de trabajo y que, por ello, se había producido.

${ }^{17}$ GARCÍA GONZÁLEZ, Guillermo. Los inicios de la previsión social en España: responsabilidad patronal y seguro de accidentes en la ley de accidentes del trabajo de 1900. Op. Cit., pp. 1-32.

${ }^{18}$ La máquina de vapor y su utilización en la industria.

${ }^{19}$ Hay que señalar en este sentido que lo mismo que estaba ocurriendo en España venía dándose en el resto de los países europeos.

${ }^{20}$ GARCÍA GONZÁLEZ, Guillermo. Los inicios de la previsión social en España: responsabilidad patronal y seguro de accidentes en la ley de accidentes del trabajo de 1900. Op. Cit., pp. 1-32.
} 
en basar los hechos en la responsabilidad por riego objetivo ${ }^{21}$, es decir, se imputaba la responsabilidad al patrono independientemente de que hubiese existido o no culpa del mismo en el accidente sufrido por el operario. Esto suponía que la responsabilidad se basaba, únicamente, en la existencia de un riesgo derivado de la prestación de servicios por parte del operario y el uso de las nuevas tecnologías de la época en el desempeño de sus funciones; así pues, con esta teoría, el patrono debería hacer frente a la indemnización por el daño sufrido ya que era el que utilizaba y aprovechaba la fuerza del operario para su lucro ${ }^{22}$.

En definitiva, según la teoría de la responsabilidad objetiva, el patrono debía responder del daño sufrido por el operario independientemente de que hubiese mediado culpa o negligencia por su parte por ser, sin lugar a dudas, el responsable -indirecto- de originar el riesgo laboral que lo causó por ser quien se lucraba de la actividad llevada a cabo por el operario y, además, por haber introducido el uso de máquinas para una consecución de beneficios mayor ${ }^{23}$.

\section{EL NOVEDOSO CONCEPTO DE RESPONSABILIDAD PATRONAL EN LA LEY DE ACCIDENTES DE TRABAJO DE 1900: SU CONSTRUCCIÓN JURÍDICA.}

\section{Introducción}

Como señalé al principio de este estudio, el 30 de enero de 1900 se promulga la LAT. Su aprobación supone un antes y un después en materia de responsabilidad derivada de los accidentes de trabajo. La LAT fue el comienzo de la concienciación sobre la necesidad de la previsión social en nuestro país; denota el interés del Estado por atender a las situaciones de necesidad; por primera vez se reconoce normativamente la existencia del accidente de trabajo como una cusa derivada directamente de la relación laboral existente entre el patrono y el operario y, por tanto, del poder de organización del primero.

La LAT comienza con la aclaración de los términos que se deben tener en cuenta para la comprensión e interpretación de la norma; así pues, ya en su primer artículo define los conceptos: accidente de trabajo ${ }^{24}$, patrono $^{25}$ y operario ${ }^{26}$. Continúa la LAT, en su artículo tres, disgregando todos y cada uno de los sectores antes los que será de aplicación la propia norma -un largo artículo que reconoce un amplio listado ${ }^{27}$ - que nada tiene que ver

\footnotetext{
${ }^{21}$ La responsabilidad objetiva supone que un sujeto es responsable de los riesgos generados por su actividad entendiendo que media culpa -por acción u omisión-.

22 DATO IRADIER, Eduardo. Significado y representación de las leyes protectoras del trabajo. Revista general de legislación y jurisprudencia, 1909, vol. 57, nº. 114, pp. 5-28.

23 ALARCÓN CARACUEL, Manuel. y GONZÁLEZ ORTEGA, Santiago. Compendio de seguridad social. Ed. Tecnos, 1991.

24 "Toda lesión corporal que el operario sufra con ocasión o por consecuencia del trabajo que ejecuta por cuenta ajena".

25 "El particular o Compañía, propietario de la obra, explotación o industria donde el trabajo se preste".

26 "Todo el que ejecuta habitualmente un trabajo manual fuera de su domicilio por cuenta ajena".

27 " $1^{\circ}$. Las fábricas y talleres y los establecimientos industriales donde se hace uso de una fuerza cualquiera distinta de la del hombre. $2{ }^{\circ}$ Las minas, salinas y canteras. $3{ }^{\circ}$ Las fábricas y talleres metalúrgicos y de 
con la actualidad y que, por supuesto, incluía a todas aquellas profesiones que implicaban el uso de máquinas ${ }^{28}$.

\section{La responsabilidad del patrono en materia de accidentes de trabajo tras la aprobación de la Ley de Accidentes de Trabajo de 1900: La responsabilidad patronal por riesgo industrial}

La LAT estableció la responsabilidad del patrono en materia de accidentes de trabajo derivados de la prestación de servicios del operario. La propia Ley instauró su ámbito de aplicación de forma clara: por un lado, desde la perspectiva objetiva, es decir, las actividades a las que le era de aplicación y, por otro, la subjetiva, es decir, el concepto de operario ${ }^{29}$.

La LAT, en el artículo 3, estableció las actividades a las que le sería de aplicación la norma y es importante recordar lo que rezaba dicho artículo en su apartado $1^{\circ}$ en relación a la aplicación de la Ley y a qué sectores productivos afectaba: "Las fábricas y talleres y los establecimientos industriales donde se hace uso de una fuerza cualquiera distinta de la del hombre"; es de resaltar la frase donde se hace uso de una fuerza cualquiera distinta del hombre que es muy clara en lo que al objeto de la norma se refiere si bien es cierto que, después de tasar todas y cada una de las actividades comprendidas dentro del objeto de la norma, añade el supuesto $16^{\circ}$ como vía de escape para poder encuadrar todo aquello que hubiese podido quedar fuera del ámbito de aplicación estableciendo que, además, sería de aplicación en "Toda industria o trabajo similar no comprendido en los números precedentes".

Esta norma velaba por los intereses de aquellos operarios que prestaran sus servicios en una industria que realizara sus funciones dentro de dichas actividades; este listado dejaba desprotegidos a otros muchos que tenían otro tipo de actividades y que no requerían el

construcciones. Terrestres o navales. $4{ }^{\circ} \mathrm{La}$ construcción, reparación y conservación de edificios, comprendiendo los trabajos de albañilería y todos sus anexos, carpintería, cerrajería, corte de piedras, pintura, etc. $5{ }^{\circ}$ Los establecimientos donde se producen o se emplean industrialmente materias explosivas o inflamables, insalubres o tóxicas. $6^{\circ}$ La construcción, reparación y conservación de vías férreas, puertos, caminos, canales, diques, acueductos, alcantarillas y otros trabajos similares. $7 .^{\circ}$ Las faenas agrícolas y forestales donde se hace uso de algún motor que accione por medio de una fuerza distinta a la del hombre. En estos trabajos, la responsabilidad del patrono existirá sólo con respeto al personal expuesto al peligro de las máquinas. $8 .^{\circ}$ El acarreo y transporte por vía terrestre, marítima y de navegación interior. $9 .^{\circ}$ Los trabajos de limpieza de calles, pozos negros y alcantarillas. $10^{\circ}$. Los almacenes de depósito y los depósitos al por mayor de carbón, leña y madera de construcción. $11^{\circ}$. Los teatros, con respecto de su personal

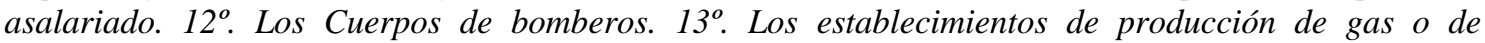
electricidad y la colocación y conservación de redes telefónicas. 14 . Los trabajos de colocación, reparación y desmonte de conductores eléctricos y de pararrayos. $15^{\circ}$. Todo el personal encargado en las faenas de carga y descarga. $16^{\circ}$. Toda industria o trabajo similar no comprendido en los números precedentes".

${ }^{28}$ Es lógico que no se incluyesen aquellas profesiones que no implicaran el uso de las máquinas ya que había sido esta nueva circunstancia la que había supuesto la elaboración y aprobación de la norma por lo que -bien entendida la lógica de aquella época- quedaban fuera todas las profesiones que no implicasen el uso de las mismas.

${ }^{29}$ GARCÍA GONZÁLEZ, Guillermo. Los inicios de la previsión social en España: responsabilidad patronal y seguro de accidentes en la ley de accidentes del trabajo de 1900. Op. Cit., pp. 1-32. 
uso de maquinaria. La solución para este tipo de trabajadores se regía por el régimen de responsabilidad común basado en la culpa del patrono regulada por el Código Civil ${ }^{30}$.

De todo ello se desprende que la responsabilidad del patrono solo afectaba en el caso de accidentes sufridos por los operarios que, según su definición, implica que realice un trabajo manual habitual, por cuenta ajena y fuera de su domicilio.

El artículo 2 de la LAT estableció que "El patrono es responsable de los accidentes ocurridos a sus operarios con motivo y en el ejercicio de la profesión o trabajo que realicen, a menos que el accidente sea debido a fuerza mayor, extraña al trabajo en que se produzca el accidente". Este era, sin duda, el objeto máximo de la norma: establecer cuándo el patrono era responsable de los accidentes de trabajo sufridos por sus operarios $\mathrm{y}$, en este sentido, era clara y concisa. Íntimamente relacionado con el artículo tres -tratado con anterioridad- y, por supuesto, con el artículo 4 de la misma norma que establecía las incapacidades reconocidas ${ }^{31}$ y las cuantías con las que debía resarcirse al operario ${ }^{32}$ además de establecer la obligación de facilitarle al mismo tanto la asistencia sanitaria como la farmacéutica hasta que este sanase o no la requiriese, así como la obligación de hacerse cargo de los gastos del sepelio -no superiores a 100 pesetas- e indemnizar ${ }^{33}$-u otorgar prestaciones vitalicias ${ }^{34}$ - a la viuda en caso de fallecimiento del operario.

\section{La Ley de Accidentes de Trabajo: El seguro de accidentes de trabajo}

El seguro de accidentes de trabajo como tal se regula por primera vez en España en el artículo 12 de la $\mathrm{LAT}^{35}$, otorgando a los patronos la posibilidad de contratar un seguro

\footnotetext{
${ }^{30}$ DE LA VILLA GIL, Luis Enrique. La influencia de la Ley de Accidentes de Trabajo de 1900 en la construcción del ordenamiento laboral español. En Derecho del trabajo y seguridad social: cincuenta estudios del profesor Luis Enrique de la Villa Gil: Homenaje a sus 50 años de dedicación universitaria. 2006. p. 103-142. En GARCÍA GONZÁLEZ, Guillermo. Los inicios de la previsión social en España: responsabilidad patronal y seguro de accidentes en la ley de accidentes del trabajo de 1900. Op. Cit., pp. 132.

${ }^{31}$ Incapacidad temporal, incapacidad permanente y absoluta -o perpetua- o incapacidad parcial-

${ }^{32}$ Para incapacidad temporal: una indemnización igual a la mitad de su jornal diario desde el día en que tuvo lugar el accidente hasta el en que se halle en condiciones de volver al trabajo; para incapacidad permanente y absoluta: igual al salario de dos años -dieciocho meses si se podía dedicar a otra profesión-; para incapacidad parcial permanente: el patrono quedará obligado a destinar al obrero con igual remuneración a otro trabajo compatible con su estado, o a satisfacer una indemnización equivalente a un año de salario a elección del patrono.

33 "Con una suma igual al salario medio diario de dos años que disfrutaba la víctima cuando esta deja viuda e hijos o nietos huérfanos que se hallasen a su cuidado. Con una suma igual a dieciocho meses de salario si solo dejase hijos y nietos. Con un año de salario a la viuda sin hijos ni otros descendientes del difunto. Con diez meses de salario a los padres o abuelos si no dejase viuda ni descendientes y fuesen estos sexagenarios y careciesen de recursos siempre que los descendientes sean dos o más".

34 "El propietario de los establecimientos industriales comprendidos en el artículo $3^{\circ}$ podrán, en vez de las indemnizaciones establecidas en el artículo $5^{\circ}$, otorgar pensiones vitalicias, siempre que las garantice a la víctima o sus derechohabientes en la forma y cuantía siguiente: 1. De una suma igual al 40\% del salario anual de la víctima, pagadera a la viuda, hijos o nietas menores de dieciséis años. 2. Del $20 \%$ a la viuda sin hijos ni descendientes legítimos de la víctima. 3. 10\% para cada uno de los ascendientes pobres y sexagenarios, cuando la víctima no dejase viuda ni descendientes, siempre que el total de estas pensiones no exceda del $30 \%$ del salario. Estas pensiones cesarán cuando la viuda pasare a ulteriores nupcias y respecto de los hijos o nietos cuando llegasen a la edad señalada en el artículo $5^{\circ}$ ".

35 "Los patronos podrán sustituir las obligaciones [...] por el seguro hecho a su costa en cabeza del obrero de que se trate, de los riesgos a que se refiere cada uno de esos artículos respectivamente o todos ellos, en
} 
que sustituyese las obligaciones previstas para ellos en la propia Ley a través de un seguro voluntario a favor del obrero que cubriese todos y cada uno de los riesgos que se reflejaban en la propia norma como obligatorios, sin embargo, la cantidad que percibiese el obrero no debía ser, en ningún caso, inferior a la que le correspondería con arreglo a la LAT.

Cierto es que nada tiene que ver con la concepción de la cobertura que tenemos hoy en día pero se puede considerar, sin lugar a dudas, como la base del seguro social obligatorio ya que hay que tener en cuenta que esta modalidad ya contemplaba la posibilidad del establecimiento de un seguro de cobertura cuyo coste debía soportar el patrono y, además, aparecieron las prestaciones reguladas normativamente -incluso en el caso en el que el accidentado no tuviese descendientes o fuese soltero-.

El propio artículo 12 de la LAT, además, deja ya un esbozado el concepto de lo que más adelante se convertiría en las mutuas patronales ${ }^{36}$ que perduran en nuestros días -si bien es cierto que modernizadas y adaptadas- ${ }^{37}$.

El seguro que reconocía la LAT era un seguro que suscribía el patrono para todos y cada uno de los accidentes laborales -siniestros laborales- que se produjesen como consecuencia del trabajo llevado a cabo por un operario en sus instalaciones -las reconocidas como protegidas en la Ley- por lo que, obviamente, el patrono podía asegurar todas y cada una de las obligaciones para con el operario desprendidas de la propia LAT; dicho esto, de las características del seguro voluntario establecido en la LAT podemos señalar las siguientes:

a. El carácter voluntario del seguro de accidentes: El propio artículo 12 de la LAT lo configura como un seguro de carácter voluntario para el patrono ${ }^{38}$. Este carácter voluntario podía suponer, en algunos casos, problemas importantes para el operario debido a la posible declaración de insolvencia del patrono o a su desaparición lo cual supondría que el operario dejaría de percibir lo que le correspondía ${ }^{39}$. Esta

una Sociedad de seguros debidamente constituida, que sea de las aceptadas para ese efecto por el Ministerio de la Gobernación, pero siempre a condición de que la suma que el obrero reciba no sea inferior a la que correspondiera con arreglo a esta ley".

${ }^{36}$ Con incorporación voluntaria para el patrono, de naturaleza privada con el requisito de autorización para intervenir en la cobertura de los accidentes de trabajo.

${ }^{37}$ SEMPERE NAVARRO, Antonio Vicente. Régimen jurídico de las mutuas patronales. Ed. Civitas, 1986; en GARCÍA GONZÁLEZ, Guillermo. Los inicios de la previsión social en España: responsabilidad patronal y seguro de accidentes en la ley de accidentes del trabajo de 1900. Op.Cit., pp. 1-32.

${ }^{38} \mathrm{Si}$ no contrataba las coberturas mediante este tipo de seguros debía hacer frente él mismo de su bolsillo de los costes que pudiesen derivarse de los accidentes de sus operarios.

${ }^{39}$ La LAT carecía de una regulación sobre insolvencia del empresario a diferencia de otras normas similares como la francesa (PIC, P. Estudio crítico de la Ley de accidentes de trabajo francesa de 9 de abril de 1898: Estudio preliminar y traducción Icíar Alzaga Ruiz. Editorial Universitaria Ramón Areces, 2002). 
característica se modificaría con el paso de los años ${ }^{40}$ hasta llegar al carácter obligatorio de la suscripción de este tipo de seguros de carácter profesional ${ }^{41}$.

b. Un seguro de carácter mercantil y privado: Por todo lo anotado con anterioridad se desprende, claramente, que el contrato de seguro que suscribía el patrono -en aquel momento- tenía carácter mercantil -en realidad estaba asegurando su situación frente al riesgo del operario-, si bien es cierto que había una clara intervención del Estado para poder ejercer el poder de vigilancia del mismo hacia dichas circunstancias estableciendo, además, normativamente ${ }^{42}$ que aquellas compañías que quieran asegurar al patrono en materia de accidentes de trabajo deberán hacerlo separando estos de otro tipo de seguros.

c. La cobertura: La cobertura que debía contratarse en este tipo de seguros era clara: la responsabilidad del patrono ante los accidentes laborales establecidos y reconocidos en la LAT de 1900.

d. Tipo de seguro individual y/o colectivo: El artículo 12 de la LAT da respuesta clara a este supuesto: el contrato de seguro podía suscribirse tanto de manera individual como colectiva.

En resumen, es en la LAT, por primera vez -lógico dado el carácter y el alcance de la norma-, cuando aparece en el derecho español el término "Inválido de Trabajo". El ostentar dicha condición supondría la adquisición de una serie de derechos, novedosos en la época, para el operario afectado; así pues, incluiría la asistencia sanitaria ${ }^{43}$ y la indemnización que tenía derecho a percibir por parte del patrono y de la que he hablado anteriormente -ambas cuestiones a cargo del empresario-.

Se estableció la obligatoriedad del patrono de indemnizar al operario por el accidente laboral sufrido con unas tablas tasadas y establecidas en la propia LAT $^{44}$. Las indemnizaciones, también a tenor de la Ley, eran variables en función de las

\footnotetext{
${ }^{40}$ Es cierto que se solicitó por parte de las asociaciones sindicales como una mejora en la reforma de la LAT en 1907 pero, finalmente, la propuesta no tuvo éxito pero sí incluyó el Fondo especial de Garantía que pretendía la constitución de mutuas que pudiesen responder en nombre del patrono y, si ello no fuese posible, sería el propio Estado quien respondería de la deuda para con el operario mediante responsabilidad subsidiaria (GARCÍA GONZÁLEZ, Guillermo. Los inicios de la previsión social en España: responsabilidad patronal y seguro de accidentes en la ley de accidentes del trabajo de 1900. Op.Cit., pp. 132.)

${ }^{41}$ Finalmente sería en 1932 cuando se instauraría la obligatoriedad del seguro de accidentes de trabajo con la reforma de la Ley por Largo Caballero.

${ }^{42}$ Real Decreto de 28 de Julio de 1900 por el que se aprueba el Reglamento de desarrollo de la Ley de Accidentes de Trabajo de 30 de enero de 1900 en su artículo 71.

43 Desarrollado por el artículo 6 del Reglamento de 28 de julio de 1900 que obligaba al patrono a ofrecer la necesaria asistencia sanitaria -auxilios sanitarios-, por un facultativo designado por el propio patrono y a quien este debía satisfacer los honorarios. A partir de la aprobación de dicha norma las industrias y las mutuas patronales crearon infraestructuras médicas y hospitalarias suficientes -este tipo de instalaciones eran mínimas a principio del siglo XX en España- (PONS PONS, Jerònia. Las mutuas patronales y la gestión del seguro de accidentes de trabajo en España hasta su incorporación a la Seguridad Social (190201966). En El trabajo y sus riesgos en la época contemporánea: Conocimiento, codificación, intervención y gestión. Publicacions i Edicions de la Universitat de Barcelona, 2012. pp. 253-286).

${ }^{44} \mathrm{Y}$ así lo establecía el artículo 4 de la LAT en el que se reconocía el derecho a la percepción de una indemnización por todo operario que hubiese sufrido un siniestro laboral con motivo y en el ejercicio de su trabajo habitual -siempre y cuando fuese de los reconocidos a tenor literal de la norma-.
} 
características personales y familiares del operario accidentado y, además, podían ser sustituidas por pensiones vitalicias para sus causahabientes ${ }^{45}$.

La LAT fue, sin duda, el inicio del sistema de previsión social en España. El Estado, dado el cambio que se había producido en el sistema productivo, no tuvo más opción que participar de manera activa en la subsanación de aquellas situaciones que influían de manera negativa y reiterada en las relaciones laborales de la época.

Lo fundamental de esta etapa es que la LAT reguló el riesgo profesional y, en su primer estadio, el seguro de accidentes de trabajo, voluntario en aquella época pero con garantías por parte del Estado para su efectivo cumplimiento de una forma u otra: la doctrina del riesgo profesional.

\section{LA RESPONSABILIDAD DEL EMPLEADOR DESDE 1922 HASTA 1995}

\section{La Ley de accidentes de trabajo de 1922}

A lo largo de los años se intentaron varias reformas fallidas que trataban de incluir toda la jurisprudencia que se había ido generando a lo largo de los años desde la aprobación de la LAT y con las que se quería suplir carencias detectadas en la misma.

Es importante resaltar aquí que en la III Conferencia Internacional del Trabajo celebrada en 1921, España ratifica ${ }^{46}$ el Convenio de la Organización Internacional del Trabajo -en adelante OIT-, sobre la indemnización por accidentes de trabajo en la agricultura. A partir de dicha ratificación, España debió introducir las modificaciones que fuesen necesarias en nuestro ordenamiento jurídico para, así, adaptarlo a los mandatos establecidos en el Convenio ratificado de dicha organización internacional.

Es el 10 de enero de 1922 cuando se produce la primera gran reforma de la LAT; así pues, se aprueba la Ley de accidentes de trabajo de $1922^{47}$-conocida como Ley Matos-.

Como ya apunté, la LAT de 1900 establecía el principio de responsabilidad objetiva del patrono en su artículo $2^{48}$ así como la obligación de indemnizar al operario por incapacidad -temporal o permanente- o por muerte; pues bien, dicho principio de responsabilidad objetiva se mantuvo en la LAT de 1922 con algunas precisiones sobre el citado artículo 2 que quedó redactado incluyendo además que, “...la imprudencia profesional, o sea la que es consecuencia del ejercicio habitual de un trabajo, no exime al patrono de responsabilidad".

\footnotetext{
45 Artículo 10 de la LAT.

${ }^{46}$ A través del Decreto de 9 de mayo de 1931 de ratificación del Convenio de la OIT sobre la protección de los accidentes de trabajo en la agricultura publicado en la Gaceta (antiguo BOE), de 11 de mayo de 1931. ${ }^{47}$ De ahora en adelante Ley Matos.

48 "El patrono es responsable de los accidentes ocurridos a sus operarios con motivo y en el ejercicio de la profesión o trabajo que realicen, a menos que el accidente sea debido a fuerza mayor, extraña al trabajo en que se produzca el accidente".
} 
Otra de las mejoras incluidas en la LAT de 1922 sobre la de 1900 es la posibilidad del aseguramiento $^{49}$ de la responsabilidad empresarial ${ }^{50}$ establecido en el artículo 25 de la misma que establecía que "Los patronos podrán sustituir las obligaciones definidas en los artículos... por el seguro, hecho a su costa, en favor del obrero, de los riesgos a que se refiere cada uno de esos artículos..." estableciendo dos posibilidades para contratar dicho seguro: mediante las mutualidades patronales ${ }^{51}$ o mediante las sociedades de seguros. En el caso de las mutualidades patronales, además, aclara la LAT de 1922 que se trata de entidades especializadas en el aseguramiento de la responsabilidad objetiva del patrono y establece para ellas una serie de requisitos importantes como son la exención de impuestos ${ }^{52}$ y el fomento de las mismas ${ }^{53}$ a través del Instituto Nacional de Previsión Social ${ }^{54}$-en adelante INP-.

Es la LAT de 1922 la que, además, establece un nuevo mecanismo que es una clara declaración de intenciones del Estado para con el tema relacionado con los accidentes de trabajo y la previsión social: la creación de un fondo especial de garantía ${ }^{55}$ que se encargará de gestionar el pago inmediato de las indemnizaciones en caso de que los obligados a ellos -patronos, mutualidades o compañías de seguro- no lo hagan. El fondo desde el cual el Estado se haría cargo de las mismas sería un fondo creado a través de un recargo sobre la contribución industrial y que administraría el INP. Se puede considerar que aspectos como este de la LAT de 1922 se vislumbra la intención del Estado de publificar los riesgos sociales lo que supondría, sin lugar a dudas, la base para la creación del sistema de seguridad social del que hoy en día disfrutamos.

\section{La Ley Bases de 1932}

En 1931, ya en época de la II República, España ratificó el Convenio número 12 de la OIT sobre indemnizaciones de los accidentes del trabajo en la agricultura que supondría la redacción y aprobación del Decreto de 12 de junio de 1931, para la fijación de las Bases para la aplicación a la agricultura de la Ley de Accidentes del Trabajo ${ }^{56}$.

La Ley de Bases de $1932^{57}$-en adelante LB- sigue manteniendo la esencia de la LAT de 1900 y, por tanto, de la modificación sustancial sufrida en 1922; el lapso de tiempo entre la aprobación de la LAT -en 1900- y 1932 supuso que el seguro de accidentes -de carácter

\footnotetext{
${ }^{49}$ La obligatoriedad del mismo llegaría a nuestro país con la Ley de 4 de julio de 1932, que modificaba el Código de Trabajo en referencia al aseguramiento. Esta Ley, junto con los Decretos de 8 de octubre de 1932 y de 31 de enero de 1933, establecieron la obligatoriedad en el contrato de seguros por parte de los patronos en materia de accidentes de trabajo lo que supone el paso definitivo hacia la publificación de las prestaciones y que, hoy en día, conocemos con el nombre de automaticidad de las prestaciones.

${ }^{50}$ Se puede decir que sería la base de los futuros seguros sociales.

${ }^{51}$ Esté fue el "nacimiento" de una serie de instituciones que han llegado hasta nuestros días: las Mutuas de Accidentes de Trabajo y Enfermedades Profesionales de la Seguridad Social.

52 Artículo 27 de la LAT de 1922.

53 Artículo 31 de la LAT de 1922.

${ }^{54}$ Que las orientaría y les otorgaría asistencia técnica.

55 Artículo 28 de la LAT de 1922.

${ }^{56}$ Por la vía del Decreto de 25 de agosto de 1931.

${ }^{57}$ Conocida como la Ley Largo Caballero.
} 
voluntario hasta este momento tal y como hemos podido ver a lo largo de las páginas anteriores-, fuese convirtiéndose, poco a poco, en un seguro obligatorio ${ }^{58}$.

Con la LB de 1932 se ampliaron los colectivos a los que les era de aplicación la protección de la norma, estableció la obligatoriedad del seguro empresarial, garantizaría las coberturas y estableció la asistencia médica de las mutualidades de trabajo. La norma que, definitivamente, instauraría en nuestro país la obligatoriedad del aseguramiento sería la Ley de Bases del Seguro Social de 4 de julio de $1932^{59}$ que modificó el Código de Trabajo y que en su Base 2 establecía que "Todo obrero de tales Empresas se considerará de derecho asegurado, aunque no lo estuviera su patrono. En el caso de que éste no indemnizare al obrero o a sus derechohabientes en el plazo que se señale, la indemnización será abonada con cargo al fondo de garantía ${ }^{60 "}$.

En definitiva, el empresario, por primera vez de manera obligatoria, debía pagar una cantidad de dinero a la entidad aseguradora -mutua o compañía de seguros- para que respondiese en su nombre en caso de que un operario sufriera un accidente de trabajo y debiera indemnizarlo en caso de incapacidad o muerte -a él o a sus beneficiarios- siendo el gestor y garante de dicho pago el Estado a través del INP. La protección de los obreros frente a los accidentes de trabajo siguió rigiéndose por la responsabilidad patronal directa, aunque el aseguramiento de las indemnizaciones correspondientes pudiese contratarse a través de mutuas o compañías de seguros o en el INP ${ }^{61}$.

\section{Decreto de 22 de junio de 1956 por el que se aprueba el Texto Refundido de la Legislación de Accidentes de Trabajo}

El Decreto de 22 de junio de 1956 por el que se aprueba el Texto Refundido de la Legislación de Accidentes de Trabajo de 1956 -en adelante TRLAT- trató de unificar toda la legislación existente en materia de accidentes de trabajo incluyendo a los trabajadores del sector agrícola para el disfrute de los beneficios establecidos, con anterioridad, para los operarios de las industrias e incluyendo mejoras en todos los ámbitos. Se refundió, además, con la LB de 8 de octubre de 1932.

El propio capítulo I del TRLAT es el que se ocupaba de regular la responsabilidad en materia de accidentes de trabajo; así pues, en los tres primeros artículos estableció las definiciones de accidente de trabajo ${ }^{62}$, patrono y trabajador.

\footnotetext{
${ }^{58}$ GARCÍA GONZÁLEZ, Guillermo. Los inicios de la previsión social en España: responsabilidad patronal y seguro de accidentes en la ley de accidentes del trabajo de 1900. Op.Cit., pp. 1-32.

${ }^{59}$ Y los Decretos de 8 de octubre de 1932 y de 31 de enero de 1933.

${ }^{60}$ Administrado por la Caja Nacional de Seguro contra accidentes de trabajo creada por INP; si bien es cierto que podían optar por hacerlo a través de una mutualidad o compañía de seguro, en cuyo caso dichas entidades deberían depositar en la Caja Nacional el montante necesario para poder asegurar el abono de la indemnización del obrero o de sus derechohabientes. En definitiva, el pago siempre iba a depender, de un modo u otro, del Estado -unas veces a cargo de este y otras a cargo del dinero depositado por mutuas y compañías aseguradoras-.

${ }^{61}$ GARCÍA PADILLA, Margarita. Historia de la acción social: Seguridad Social y asistencia, en AA.VV., Historia de la acción social pública en España. Beneficencia y Previsión, Ministerio de Trabajo y Seguridad Social, Madrid, 1990, p. 408.

${ }^{62}$ Llama la atención que la definición dada a accidente de trabajo no varía en gran medida de la que utilizamos en la actualidad; así pues, el artículo 1 establecía que "A los efectos de la presente Ley, se
} 
Los artículos 6 y 7 eran los que regulaban la responsabilidad en materia de accidentes de trabajo. Según la TRLAT eran indemnizables todos los accidentes de trabajo que cupiesen dentro de la definición del artículo 1, es decir, los sufridos a casusa de la relación de trabajo ${ }^{63}$ por cuenta ajena excepto en el caso de que medie fuerza mayor ${ }^{64}$ y establecía, además, que la imprudencia del trabajador no eximía al patrono de la responsabilidad nacida del accidente de trabajo y apareciendo ya el término prevención de riesgos laborales, eso sí, de manera somera, además, estableció un mecanismo de infracciones para el incumplimiento de la falta de aseguramiento de los operarios por parte de los empleadores ya que estos continuaron siendo los responsables directos del pago de las mismas.

\section{Ley de Bases de Seguridad Social de 28 de diciembre de 1963}

La Ley de Bases de la Seguridad Social -en adelante LBSS- se publicó 28 el de diciembre de $1963^{65}$. Esta, junto con la de 1966 y la Ley General de Seguridad Social de 1974, sería, sin lugar a dudas, las normas que consiguieron unificar los diferentes seguros sociales y crear el sistema de seguridad social que hoy en día conocemos estableciendo parámetros contributivos que trataban de proteger tanto a los trabajadores por cuenta ajena como a sus beneficiarios. Con esta norma nació un nuevo sistema de seguridad social que se centró en la acción protectora desde un punto de vista contributivo.

La LBSS de 1963 supuso una reforma importante de la previsión social en España; fue un documento de sistematización en materia de seguridad social que unificó la dispersión legislativa existente en la materia y, además, supuso la aparición de derechos y deberes importantes y novedosos en la materia que acababan con lo conocido hasta aquel momento y fundaban las bases de un nuevo sistema de seguridad social ${ }^{66}$.

En el preámbulo de la LBSS de 1963 se puede leer que "Los problemas más arduos y difíciles comienzan cuando el siniestro ha concluido de surtir sus efectos inmediatos, dejando tras sí la secuela de una invalidez permanente. La recuperación física o fisiológica del inválido cuando ésta es posible, o en otro caso, su readaptación y reentrenamiento para una nueva profesión son objetivos a cumplir, tanto desde el punto de vista estrictamente humano e individual, devolviendo al inválido la conciencia de su dignidad personal y de su utilidad social, cuanto desde el punto de vista económico al hacer posible su reincorporación al proceso productivo". Este párrafo de la LBSS de 1963 deja clara la intención del legislador en materia de accidentes de trabajo.

entiende por accidente toda lesión corporal que el trabajador sufra con ocasión o por consecuencia del trabajo que ejecute por cuenta ajena".

${ }^{63}$ Los que ocurran en todas las industrias y trabajos de cualquier naturaleza -siempre que entren en los regulados en la norma-.

${ }^{64}$ Es curioso que no se consideraba fuerza mayor la insolación, el rayo y otros fenómenos naturales análogos.

65 Presentada al Consejo de Ministros en San Sebastián el 9 de agosto y remitida a las Cortes el 11 de octubre de ese mismo año.

${ }^{66}$ MARAVALL CASESNOVES, Héctor. La Ley de Bases de la Seguridad Social y el Seguro de accidentes de trabajo. Revista de Política Social, 1964, nº 61, pp. 253-271. 
La LBSS supuso la nueva concepción del sistema de seguridad social español y, así, las contingencias serían protegidas y, además, garantizadas por el Estado; la protección se otorgaría a todas las situaciones de necesidad independientemente de cómo se hubiesen producido -ni siquiera hoy en día estamos ante un sistema de seguridad social totalmente universal-. La LBSS de 1963 intentó romper, por primera vez desde 1900, con la responsabilidad empresarial para reconducir las indemnizaciones por accidente al sistema general de la seguridad social -si bien no se consiguió totalmente-. En la Base Quinta, artículo 18 de la LBSS de 1963 se establecía que quedaba protegido mediante lo operado en dicha norma el accidente -fuese o no de trabajo- así como las prestaciones económicas necesarias en los casos previstos legalmente ${ }^{67}$; en el artículo 20 obligaba a la prevención de los accidentes de trabajo y, lo más importante, estableció la base de cotización para accidentes de trabajo en su artículo 55 de manera que los empleadores eran los obligados principales al pago íntegro de la cotización por este concepto, en el artículo 61 se creó el Instituto Nacional de Seguridad, Rehabilitación y Accidentes de Trabajo y, en el artículo 62, se estableció la posibilidad de las empresas de participar en la gestión de la seguridad social en relación a las prestaciones por accidentes de trabajo.

\section{Ley de Seguridad Social de 21 de abril de 1966}

La LBSS de 1963 supuso la base clara del Texto Articulado de la Ley de Seguridad Social de 1966 -en adelante TALSS-. La pretensión del TALSS era, sin lugar a dudas, poner fin a la pluralidad de cobros de las prestaciones en caso de accidentes de trabajo -también de enfermedades profesionales- $\mathrm{y}$, por supuesto, la mejora de las prestaciones del sistema. Pretendía el legislador una reforma que mejorara el sistema que se utilizaba hasta ese momento en referencia a los accidentes de trabajo y, además, centrar el pago de las prestaciones en una sola entidad si bien es cierto que todavía existían antiguos sistemas de cotización, no se revalorizaban los salarios y no había idea de unidad. En aquel momento, las mutuas patronales pasaron a convertirse en mutuas colaboradoras de la seguridad social.

En este sentido surge la unificación del sistema anterior con la nueva concepción de seguridad social; la LBSS de 21 de abril comprendía ya en el campo de aplicación de la seguridad social a todos los españoles sin establecer diferenciaciones en aspectos tales como el sexo, estado civil o, la novedad que más me interesa en este estudio, la profesión a la que se dedicasen y estableció la obligatoriedad de afiliación al sistema de seguridad social como tal siendo obligación directa y responsabilidad del empleador y recayendo en estos la obligación de cotizar por las personas trabajadoras que para ellos prestaran servicios por cuenta ajena -encargándose de la recaudación las entidades gestoras de la seguridad social-.

La acción protectora de la seguridad social incluía ya en esta norma: la asistencia sanitaria en los casos de maternidad, enfermedad y accidente -sean o no del trabajo-, las

67 “...incapacidad laboral transitoria, invalidez, vejez, desempleo, muerte y supervivencia, así como las que se otorguen en contingencias y situaciones especiales que se regulen”. 
prestaciones económicas por incapacidad, invalidez, desempleo y muerte y supervivencia, las de protección a la familia y los servicios sociales.

En referencia a la responsabilidad de los empresarios en materia de accidentes de trabajo el TALSS establecía la responsabilidad de los mismos de satisfacer las cotizaciones al sistema si bien es cierto que las obligadas al pago de las prestaciones ${ }^{68}$ eran, desde aquel momento, las entidades gestoras dejando ya a un lado el seguro privado obligatorio que los empleadores se habían visto obligados a contratar en las épocas anteriores; es decir, a partir de la aprobación del TALSS existía una corresponsabilidad entre el empresario y las entidades gestoras de la seguridad social.

Otra novedad que, como se verá, sigue en vigor hoy en día es la que introdujo el artículo 147 del TALSS y que establecía un recargo en las prestaciones que, en aquel momento, consistía en una cantidad a tanto alzado cuando un trabajador hubiese sufrido un accidente de trabajo ${ }^{69}$, de entre un $30 \%$ y un $50 \%$-como se puede ver muy similar al sistema que existe en la actualidad- que recaería, directamente, sobre el empresario infractor no existiendo la posibilidad de asegurar el recargo -como ya se verá son características que hoy en día siguen operando en el mismo sentido-. El mismo artículo en su último apartado estableció un sistema de compatibilidad entre las responsabilidades de todo orden, es decir, la percepción de dicho recargo con las responsabilidades civiles o penal que pudiesen recaer sobre la persona del empleador.

\section{Ley General de la Seguridad Social de 30 de mayo de 1974}

El Texto Refundido de la Ley General de la Seguridad Social de 1974 -en adelante el TRLGSS- no recoge en ningún Título el accidente de trabajo, ahora bien, este ocupa más de una quinta parte del texto legislativo de 1974 estableciendo en su regulación las prestaciones sanitarias, recuperadoras y económicas del accidente de trabajo. A partir de entonces las mutuas de accidentes de trabajo y enfermedades profesionales quedaban exentas de la cobertura privada de sus orígenes para, así, incluirlas en la estructura del sistema de seguridad social.

La idea del recargo de las prestaciones seguía aplicándose según la norma de 1974 recayendo el pago del mismo en la figura del empleador sin posibilidad de aseguramiento de las mismas y en los mismos porcentajes que ya se establecieron en la LBSS de 1966 así como el tema derivado del resto de indemnizaciones que el trabajador podía percibir sin que fuesen, de nuevo, incompatibles.

\footnotetext{
${ }^{68}$ Y así lo establecía el artículo 68 de la LSS.

69 “'Cuando la lesión se produzca en máquinas, artefactos, instalaciones o centros y lugares de trabajo que carezcan de los dispositivos de precaución reglamentarios, los tengan inutilizados o en malas condiciones o en los que no se hayan observado las medidas generales o particulares de seguridad e higiene en el trabajo o las elementales de salubridad o adecuación al trabajo".
} 


\section{Ley General de la seguridad social, Real Decreto Legislativo 1/1994 de 20 de junio de 1994}

Igual que en el caso anterior ocurrió con el texto de la Ley General de Seguridad Social en adelante LGSS- de $1994^{70}$. En este texto aparece de nuevo el concepto de accidente de trabajo así como la cotización que corresponde a este tipo de contingencias y su correspondiente prestación y sigue en el mismo sentido que la anterior en lo que a indemnizaciones y responsabilidad empresarial se refiere.

\section{LA RESPONSABILIDAD DEL EMPRESARIO EN MATERIA DE ACCIDENTES DE TRABAJO EN LA ACTUALIDAD}

\section{Introducción}

La Ley de Prevención de Riesgos Laborales -en adelante LPRL-, el Texto Refundido de la Ley General de Seguridad Social -en adelante TRLGSS-, La Ley sobre Infracciones y Sanciones del Orden Social -en adelante LISOS-, el propio Estatuto de los Trabajadores -en adelante ET- $^{71}$, regulan tanto las obligaciones como las responsabilidades en materia preventiva -lo que incluye, lógicamente, los accidentes de trabajo-.

En materia de responsabilidad del empleador y tras la evolución sufrida a lo largo de los años, en la actualidad, tienen una cuádruple responsabilidad: civil, penal, administrativa y en materia de seguridad social derivadas, directamente, de la regulación en materia de prevención de riesgos laborales de la Ley 31/95, de 8 de noviembre, de Prevención de Riesgos Laborales. Este tipo de responsabilidades son, sin lugar a dudas, las que fomentan, en gran medida, el cumplimiento de los mandatos establecidos en la LPRL -tal y como ocurre con el resto de normas y en los diferentes ámbitos del derecho en general, si bien es cierto que se ven apoyadas por los mecanismos de control de las instituciones del Estado, tales como la Inspección de Trabajo, o las organizaciones sindicales ${ }^{72}$.

Es importante resaltar que este tipo de sanciones pueden producirse antes de que ocurra un accidente siempre que se detecten irregularidades o a posteriori si una vez se lleva a cabo la investigación del accidente se demuestra que se ha producido por incumplimiento de la normativa en materia de PRL o deficiencia en otros campos que ha conllevado el final trágico.

Si pensamos en la responsabilidad penal o en la responsabilidad administrativa, obviamente, centramos nuestro interés en el incumplimiento de la norma mientras que si estudiamos la razón de ser de la responsabilidad civil entenderemos que su finalidad no es otra que la de resarcir el daño producido teniendo en cuenta cuales han sido las

\footnotetext{
${ }^{70}$ Vigente en nuestro ordenamiento jurídico hasta la aprobación del TRLGSS el 30 de octubre de 2015.

${ }^{71} \mathrm{Y}$ todas las normas que desarrollan dichas leyes.

72 VALDEOLIVAS GARCÍA, Yolanda. El modelo de responsabilidad empresarial por incumplimiento de obligaciones de prevención de riesgos laborales. 2011. RJUAM, p. 42.
} 
consecuencias del accidente y, por tanto, la protección de la persona trabajadora que lo haya sufrido ${ }^{73}$.

Todas y cada una de las facetas de la responsabilidad empresarial en materia de PRL persiguen el mismo fin: redundar de manera positiva en la protección de las personas trabajadoras. Es importante señalar que no existen responsabilidades de tipo penal o administrativo sino media culpa por parte del empleador.

El preámbulo de la propia LPRL establece que tiene por objeto establecer garantías y responsabilidades en materia preventiva para así poder adecuar un correcto nivel de protección de la salud de las personas trabajadoras frente a los riesgos derivados de las condiciones de trabajo. Es el artículo $42.1^{74}$ de la LPRL la que establece las responsabilidades en esta materia; así pues, funda claramente los tres tipos de responsabilidades reconocidas a lo largo de esta introducción y dejando claro que no existe incompatibilidad entre las mismas: penal, administrativa y civil.

El propio artículo 19 del ET establece el derecho de la persona trabajadora a una protección eficaz en materia de Seguridad e Higiene en la prestación de sus servicios, lo que se traduce, directamente, en la obligación del empleador a otorgarle dicha protección eficaz y, por tanto, a dotarlo de los medios necesarios para el desarrollo seguro de su actividad que se materializa, claramente, en el Capítulo III de la LPRL que regula las obligaciones del empleador derivadas, directamente, de dicho derecho -si bien es cierto que aparecen otras tantas a lo largo de todo el articulado de la LPRL-.

Es importante aclarar, además, que no únicamente el empleador es el responsable de los daños que pueda sufrir la persona trabajadora sino que, además, los servicios de prevención, las entidades auditoras y las formativas lo son de igual manera ${ }^{75}$ como también lo son los fabricantes, importadores y suministradores de maquinaria, equipos, productos y útiles de trabajo -que están obligados a garantizar que estos no son una fuente de peligro para la persona trabajadora siempre y cuando sean utilizados de manera correcta y para el fin que fueron concebidos-.

\section{La responsabilidad civil}

Este tipo de responsabilidad del empresario consiste en resarcir el daño que haya podido sufrir el trabajador a causa de un accidente de trabajo. Es la única responsabilidad en materia de accidentes de trabajo que no tiene carácter sancionador por lo que no tiene naturaleza preventiva directa ${ }^{76}$. Este tipo de responsabilidad civil es de carácter contractual y viene regulado en los artículos 1101 y ss. del Código Civil -en adelante CC-

\footnotetext{
${ }^{73}$ VALDEOLIVAS GARCÍA, Yolanda. El modelo de responsabilidad empresarial por incumplimiento de obligaciones de prevención de riesgos laborales. 2011. RJUAM, p. 43.

74 “El incumplimiento por los empresarios de sus obligaciones en materia de prevención de riesgos laborales dará lugar a responsabilidades administrativas, así como, en su caso, a responsabilidades penales y a las civiles por los daños y perjuicios que puedan derivarse de dicho incumplimiento".

${ }^{75}$ Y así lo establece el artículo 2.9 del Real Decreto Legislativo 5/2000, de 4 de agosto, por el que se aprueba el texto refundido de la Ley sobre Infracciones y Sanciones en el Orden Social.

76 VALDEOLIVAS GARCÍA, Yolanda. El modelo de responsabilidad empresarial por incumplimiento de obligaciones de prevención de riesgos laborales. Op. Cit., p. 44.
} 
ya que nace de la relación contractual existente entre empleador y personas trabajadoras -si bien es cierto que puede ser extracontractual ${ }^{77}$.

Para que pueda operar la responsabilidad civil ante los accidentes de trabajo sufridos por las personas trabajadoras debemos tener en cuenta que deben cumplirse una serie de requisitos fundamentales: tratarse de una acción antijurídica, culpable y que, además, exista un nexo causal entre el daño producido y la acción u omisión culpable del empleador.

El responsable principal será el titular de la empresa independientemente de que haya o no contratado un servicio de prevención de riesgos laborales externo y que este se encargue de las cuestiones fundamentales en materia de PRL.

Para que exista responsabilidad civil derivada de la relación contractual es necesario que, efectivamente, se haya producido un daño ${ }^{78}$ sobre la persona trabajadora que presta sus servicios por cuenta ajena $\mathrm{y}$, por tanto, a tenor del artículo 4.3 de la LPRL queda establecido que se consideran como tales las enfermedades, patologías o lesiones sufridas con motivo u ocasión del trabajo que, además, deben ser cuantificables ${ }^{79}$. Para el cálculo de las indemnizaciones ${ }^{80}$ se suele utilizar el RD Legislativo 8/2004, de 29 de octubre, por el que se aprueba el texto refundido de la Ley sobre responsabilidad civil y seguro en la circulación de vehículos a motor y en este sentido la STS de 20 de octubre de $2008^{81}$ ya estableció que era oportuno -no obligatorio- la utilización del baremo establecido para calcular las indemnizaciones para víctimas de accidentes de tráfico en la valoración de los daños por accidentes de trabajo que, además, puede aplicarse al alza en los casos en los que concurra culpa por parte del empleador y cuya cuantificación corresponde al $\mathrm{Juez}^{82}$.

Es de destacar que la exigencia de la culpa se ha llegado a flexibilizar por parte de la jurisprudencia uniendo dicho principio al de responsabilidad objetiva llegando a

77 Debemos distinguir entre los diferentes tipos de responsabilidad civil que existen: contractual, extracontractual -ya que para que esta exista no es necesario que medie un vínculo contractual- y la derivada de un delito; en el caso de los accidentes de trabajo lo habitual en materia de responsabilidad civil será que exista un vínculo contractual -laboral o mercantil- entre el empleador y la persona trabajadora o el trabajador por cuenta propia.

${ }^{78}$ Entendiendo como tal cualquier perjuicio físico, moral o económico -incluyendo el daño emergente y el lucro cesante-.

${ }^{79}$ El RD Legislativo 8/2004, de 29 de octubre, por el que se aprueba el texto refundido de la Ley sobre responsabilidad civil y seguro en la circulación de vehículos a motor, suele utilizarse por los Tribunales del orden social para calcular la indemnización adicional por responsabilidad civil en caso de accidente de trabajo o enfermedad profesional.

${ }^{80}$ Es, además, importante resaltar que la indemnización a la que tendrá derecho la persona trabajadora se establecerá teniendo en cuenta todos y cada uno de los daños individuales físicos y morales que haya sufrido a causa del daño alegado.

${ }^{81}$ Número de Recurso 3801/2007. 82

http://www.hispacolex.com/wpcontent/uploads/documents/descargas/Ponencia\%20Jose \%20Manuel\%20Lopez $\% 20 y \% 20$ Garcia $\% 20 \mathrm{de} \%$ 201a\%20Serrana.Breve.pdf. La responsabilidad civil del empresario por accidentes de trabajo. José Manuel López y García de la Serrana Magistrado del Tribunal Supremo. (Consultado el 01 de junio de 2020). 
configurar una responsabilidad cuasiobjetiva $^{83}$; en este sentido pueden percibirse diferencias dependiendo de si la misma surge de la Sala Primera o de la Sala Cuarta del Tribunal Supremo y, así, la Sala Primera acepta las soluciones cuasiobjetivas mientras que la Sala Cuarta no la aplica cuando afecta a las personas trabajadoras lo que justificaría la predilección de los afectados por la jurisdicción civil.

Es importante, no obstante, señalar que la STS Sala Cuarta, de 8 de octubre de 2001, establece que "El deber de protección del empresario es incondicional y prácticamente ilimitado Deben adoptarse las medidas de protección que sean necesarias, cualesquiera que sean. Y esta protección se dispensa aún en los supuestos de imprudencia no temeraria del trabajador. Si al patrono se le exige tal nivel de diligencia..., el puntual cumplimiento de las precauciones legales y reglamentarias así como de las que aconseje la técnica más reciente y se hace gravitar sobre él la carga de la prueba, es claro que estaremos cerca de la responsabilidad cuasiobjetiva y que las diferencias serán mínimas: No liberar de responsabilidad al patrono que probó haber actuado diligentemente, so pretexto de que el siniestro prueba que no agotó toda la diligencia debida".

El artículo 1101 del CC establece que "Quedan sujetos a la indemnización de los daños y perjuicios causados los que en el cumplimiento de sus obligaciones incurrieren en dolo, negligencia o morosidad, y los que de cualquier modo contravinieren al tenor de aquéllas" lo que desde el punto de vista del derecho del trabajo supone que el mismo ha incumplido con los deberes y obligaciones nacidos tras la existencia del contrato de trabajo y lo que este implica, en materia de PRL, sumado al daño que haya podido sufrir la persona trabajadora en estas circunstancias por lo que el empresario tendrá que resarcir a la misma salvo en los supuestos que la propia LPRL establece en su artículo 15.4 imprudencia temeraria del mismo- o en el artículo 1105 del CC -caso fortuito o fuerza mayor-.

Para la obtención de la cuantía dineraria ${ }^{84}$ derivada de la responsabilidad civil ${ }^{85}$ de empleador será la persona trabajadora quien deberá probar tanto la existencia de la culpa como la cuantificación del daño que ha sufrido siendo responsabilidad del empleador probar el cumplimiento de sus obligaciones o la existencia de alguna causa que le exoneren de la culpa ${ }^{86}$.

\footnotetext{
${ }^{83}$ Se trabaja con la idea de la responsabilidad cuasiobjetiva del empleador; es decir, aunque la responsabilidad viene regulada en primera instancia por la culpa, negligencia o mora del empleador imponiendo la responsabilidad civil del mismo independientemente de la existencia real de la culpa en el hecho acaecido -sí se tendrá esta en cuenta en los otros tipos de responsabilidades establecidos legalmente${ }^{84}$ Teniendo en cuenta el carácter patrimonial, los directos, los indirectos y los daños morales. Será determinada por el órgano jurisdiccional competente en la materia y que, además, será proporcional y adecuada al daño para poder resarcir de forma adecuada a la persona trabajadora.

${ }^{85}$ Si no existe baremo específico para el cálculo de la indemnización por daños y perjuicios se utilizará el baremo existente para el cálculo de las indemnizaciones en los accidentes de tráfico.

${ }^{86}$ Estableciendo el artículo 96.2 de la LRJS que "En los procesos sobre responsabilidades derivadas de accidentes de trabajo y enfermedades profesionales corresponderá a los deudores de seguridad y a los concurrentes en la producción del resultado lesivo probar la adopción de las medidas necesarias para prevenir o evitar el riesgo, así como cualquier factor excluyente o minorador de su responsabilidad. No podrá apreciarse como elemento exonerador de la responsabilidad la culpa no temeraria del trabajador ni la que responda al ejercicio habitual del trabajo o a la confianza que éste inspira".
} 
No debemos obviar que la responsabilidad civil del empresario se fundamenta en el artículo 1902 del CC que establece la obligación de resarcir un daño siempre que exista culpa o negligencia entendido como máximo responsable de la misma al empleador bajo cuyo cuidado debe permanecer la persona trabajadora que presta sus servicios por cuenta ajena debiendo tener en cuenta, además, que el artículo 1093 del mismo precepto legal así como el 120 del CP- establece que debe ser el empresario quien responda de las daños que sufran las personas trabajadoras que presten servicios a su cargo siempre y cuando estos se produzcan en el desempeño de sus funciones por cuenta ajena. La responsabilidad civil, además, a diferencia de la penal y la administrativa se puede cubrir con la perceptiva póliza de responsabilidad civil que se encargue de cubrir los daños derivados de los accidentes de trabajo.

En referencia a la responsabilidad civil del empleador ${ }^{87}$ hay que realizar una puntualización importante: no operará en caso de que el suceso no se haya podido prever o, en su caso, si fuese inevitable o existiese fuerza mayor ${ }^{88}$ y así lo establece el artículo 1105 del CC. Correspondiéndole la carga de la prueba a la persona del empleador ${ }^{89}$ a tenor de lo establecido en el artículo 217 de la Ley de Enjuiciamiento Civil y, por tanto, será este quien deberá probar que actuó de modo diligente adoptando las medidas necesarias para evitar el accidente de trabajo ${ }^{90}$.

El empleador quedará exonerado de la culpa en materia de responsabilidad civil a tenor de los supuestos del artículo 1105 del CC, es decir, fuerza mayor, fuerza imprevisible e inevitable si bien es cierto que en el supuesto de caso fortuito se deberá distinguir a si el daño se produjo por causa externa o interna de la empresa. En este sentido se hace necesario remarcar que la culpa atribuible a la persona trabajadora, por el contrario, no eximirá de responsabilidad civil al empleador ${ }^{91}$.

En el caso de que exista negligencia por parte del empleador, es decir, falta de la diligencia debida -si lo definimos en sentido contrario- entendemos, en palabras del propio TS, que no ha existido la perseverancia exigible y la reflexión necesaria con vistas a evitar el ${ }^{92}$ perjuicio en los bienes ajenos jurídicamente protegidos ${ }^{93} \mathrm{y}$ es de resaltar que para que no exista responsabilidad los sujetos responsables -no solo empleadores sino, además,

\footnotetext{
${ }^{87} \mathrm{Si}$ la responsabilidad incurre en más de una persona está será solidaria y no mancomunidad de modo que la persona trabajadora actuará contra quien más convenga pudiendo este reclamar al resto de responsables.

${ }^{88}$ Para que el caso concreto se entienda fortuito debe ser imprevisible o inevitable, se haya producido un daño y que exista relación causal entre el suceso y el daño.

${ }^{89}$ En relación al artículo 217 de la LECrim y, de forma supletoria, según la LEC.

${ }^{90}$ SSTS Sala Primera de 25 de enero de 1985, 8 de mayo de 1986 y 10 de julio de 2003.

${ }^{91}$ La STS de la Sala Primera de 29 de abril de 2004 dejó establecido que era necesario ampliar el concepto de culpa y tener en cuenta que puede existir negligencia - de una u otra parte- sin que exista una conducta ilegal.

92 STS, Sala Segunda de lo Penal, de 25 de abril de 1988.

${ }^{93}$ STS, Sala Primera de lo Civil, de 2 de noviembre de 1988.
} 
responsables y técnicos de PRL- deben emplear todos los medios que la prudencia demande para prevenir y evitar el daño $o^{94}$.

Debe existir, además, nexo causal, es decir, relación entre la acción u omisión llevada a cabo por el sujeto responsable -en este caso empleador o sujeto responsable de la PRLy el daño que sufra la persona trabajadora que presta sus servicios por cuenta ajena.

Es importante, además, señalar que, en algunos casos, la responsabilidad civil se acompaña de la existencia de un tipo penal -al que se hará mención en el siguiente apartado- lo que supondrá, además, que el culpable haga frente a la perceptiva condena penal -si procede- o únicamente al quantum indemnizatorio.

El empleador no será responsable siempre que pueda acreditar que ha agotado toda la diligencia que le es exigible y, además, más allá de las mismas lo que reconoce, de forma clara la responsabilidad cuasiobjetiva del empleador en materia de accidentes de trabajo 95 .

En resumen, la finalidad de dicha responsabilidad es reparar o compensar los daños sufridos por la persona trabajadora que ha sufrido accidente de trabajo. Existe la responsabilidad civil siempre independientemente de que haya existido imprudencia por parte de la persona trabajadora y, por supuesto, acciones u omisiones del empleador que haya supuesto el accidente. La prescripción de la misma está sujeta a lo establecido en el artículo 258 del CC, es decir, a los dos años a contar desde la determinación de la incapacidad o el fallecimiento de la persona trabajadora.

\section{La responsabilidad penal}

La responsabilidad penal del empresario en materia de accidentes de trabajo está articulada para abarcar las infracciones en materia preventiva por parte del empresario ya que con sus acciones y/u omisiones el empleador está poniendo en peligro a la persona trabajadora.

Es necesario realizar en este momento un inciso y es que, el Código Penal -en adelante CP- establece en su artículo 116.1 que "Toda persona criminalmente responsable de un delito lo es también civilmente si del hecho se derivaren daños o perjuicios. Si son dos o más los responsables de un delito los jueces o tribunales señalarán la cuota de que deba responder cada uno", lo que supone que cuando el empleador cause daños o perjuicios, por acción u omisión- a la persona trabajadora y tenga responsabilidad penal lleva acarreada, además, la responsabilidad civil que legalmente le corresponda.

El responsable principal en materia penal en relación a los accidentes de trabajo es el empleador ya que de él dependen las obligaciones derivadas de las normas relativas a dicha disciplina pero, no obstante, hay otra serie de sujetos implicados en la misma como pueden ser los trabajadores delegados en materia de prevención de riesgos laborales, los

\footnotetext{
${ }^{94}$ En el caso de que exista negligencia de la persona trabajadora va a establecer tanto la graduación de la responsabilidad civil del empleador como, en su caso, la exoneración del mismo y así lo establece, por ejemplo, las SSTS de 30 de junio de 2003 y de 16 de enero de 2006.

95 Y así lo reconoce la STS de 30 de junio de 2010.
} 
técnicos de prevención o todo aquel en el que el empresario haya delegado funciones relacionadas con dichas cuestiones ${ }^{96}$.

La responsabilidad penal ${ }^{97}$ en materia de PRL viene tipificada en los artículos $147^{98}, 152^{99}$ -estos dos de carácter general-, $316^{100}, 317^{101}$ y $318^{102}$-si bien, con carácter general, están contenidos los delitos contra los trabajadores en los artículos del 311 al 318 estos son los que hacen referencia al tema que me ocupa- del CP y recoge los delitos de puesta en peligro de las personas, el delito de omisión, el delito de comisión por omisión y delitos de homicidio y lesiones genéricas. Es de resaltar que, al tratarse de un delito, esta responsabilidad, lógicamente, no es asegurable por lo que se responde personalmente. En lo que se refiere a las sanciones pueden ir con penas de prisión de entre seis meses y tres años y multas de entre seis a doce meses para las personas obligadas ${ }^{103}$.

Claro es el artículo $316^{104}$ del CP al respecto del responsable directo de la infracción ${ }^{105}$ y, así pues, establece que aquellos que incumplan con las normas en materia de PRL, no faciliten los medios necesarios a las personas trabajadoras o no velen por las medidas de seguridad e higiene adecuada poniendo en peligro su vida, salud o integridad física serán castigados con penas de prisión de entre seis meses y tres años y multas de entre seis y doce meses ${ }^{106}$. El empleador, lógicamente, es el responsable directo; ahora bien, se debe tener en cuenta que también pueden serlo mandos intermedios o técnicos de prevención. Es un ejemplo claro de conducta omisiva del empleador para con la seguridad y salud de las personas trabajadoras poniendo en riesgo valores tan importantes para nuestro ordenamiento jurídico como lo son la vida y la salud de las personas trabajadoras durante el tiempo en el que estas están prestando sus servicios por cuenta ajena.

\footnotetext{
${ }^{96}$ Hasta la última reforma del Código penal las personas jurídicas no podían ser imputadas penalmente.

${ }^{97}$ Las personas trabajadoras que prestan sus servicios por cuenta ajena que han sufrido un accidente de trabajo suelen concurrir a la vía penal y acumular acciones civiles y penales.

98 "El que, por cualquier medio o procedimiento, causare a otro una lesión que menoscabe su integridad corporal o su salud fisica o mental”.

99 "El que por imprudencia grave causare alguna de las lesiones previstas en los artículos anteriores..."

100 "Los que con infracción de las normas de prevención de riesgos laborales y estando legalmente obligados, no faciliten los medios necesarios para que los trabajadores desempeñen su actividad con las medidas de seguridad e higiene adecuadas, de forma que pongan así en peligro grave su vida, salud o integridad física...”.

${ }^{101}$ Imprudencia grave relativa al artículo 316 del CP.

102 "Cuando los hechos previstos en los artículos de este título se atribuyeran a personas jurídicas, se impondrá la pena señalada a los administradores o encargados del servicio que hayan sido responsables de los mismos y a quienes, conociéndolos y pudiendo remediarlo, no hubieran adoptado medidas para ello...". ${ }^{103}$ Empresarios, mandos intermedios, técnicos de PRL, personal designado y trabajadores.

${ }^{104}$ Es de destacar que desde hace ya varios años de entre los “delitos contra los trabajadores" contemplados en el CP, el que más condenas ha supuesto es el derivado, directamente, del artículo 316 del CP, es decir, de no proporcionar medidas de seguridad suficientes a las personas trabajadoras.

$105 \mathrm{Si}$ bien es cierto que hay que aclarar que el empleador no tendrá responsabilidad penal cuando haya cumplido con todas las normas en materia de PRL y, además, haya tomado todas las medidas oportunas para que no se produzca el accidente ya estamos hablando de una obligación de medios y no de una obligación de resultados; por ello, para que un empleador pueda ser condenado es suficiente con que ponga en peligro a la persona trabajadora independientemente de que se produzca o no, como resultado, el accidente o las lesiones -o la muerte en el peor de los casos-.

${ }^{106} \mathrm{El}$ artículo 317 clarifica que si se ha cometido el delito por imprudencia grave la pena impuesta será la inferior en grado.
} 
Hay que resaltar que este tipo penal únicamente será de aplicación en los casos más graves de incumplimiento de la norma en materia de seguridad y salud en el trabajo y no a todas y cada una de las conductas dolosas de los empleadores y harán referencia a las que supongan un grave peligro para las personas trabajadoras y que, por tanto, supongan una mayor lesividad para las mismas ${ }^{107}$.

Este tipo de delitos que conllevan responsabilidad penal para el empresario están directamente relacionados con la intención punitiva del Estado y se basa en la estructura de un delito de omisión y de peligro concreto grave, es decir, como un delito de resultado que permitirá la compatibilidad entre ambos si el resultado lesivo se produce ${ }^{108}$-según el principio de consunción del artículo 8.3 del $\mathrm{CP}^{109}$-; en definitiva, el tipo delictivo del artículo 316 del CP es un delito de omisión con la exigencia de que se produzca un peligro grave para un bien jurídico importante de las personas trabajadoras -vida, salud o integridad física-

La diferencia más importante entre el tipo del artículo 316 del $\mathrm{CP}$ y el regulado en el artículo 317 del mismo es que en el primer caso el empleador ha cometido el delito por no cumplir las normas en materia de salud laboral mientras que en el segundo hace referencia a un delito imprudente ${ }^{110}$. Es imprescindible, en este tipo de responsabilidad, el papel que ha llegado a suponer la persona trabajadora en el accidente y lo que ha supuesto está en la aparición del mismo; en este sentido ha establecido la Doctrina tres importantes supuestos de los que dependerá, por un lado, la cantidad pecuniaria a recibir por el trabajador en relación a la responsabilidad civil y, por otro, en la graduación de la responsabilidad penal del empleador, por otro: la existencia del nexo causal por parte del empleador o por parte de la persona trabajadora ${ }^{111}$-en su caso-, el riesgo permitido ${ }^{112}$, que no se supere el riesgo permitido ${ }^{113}$ y si el trabajador ha llevado a cabo una conducta imprudente que le haya puesto en peligro.

El artículo 318 del CP aclara cuál va a ser el modo de actuar en el caso de que el sujeto responsable del accidente no sea una persona física sino jurídica, es decir, aplica la autoría de aplicación preferente ${ }^{114}$ pero recordemos que este tipo de responsabilidad no opera si no existe dolo o culpa ${ }^{115}$.

\footnotetext{
${ }^{107}$ STS de 29 de julio de 2002.

108 SSTS de 4 de junio de 2002 y de 22 de diciembre de 2001.

109 RODRÍGUEZ-RAMOS LADARIA, Gabriel. Código Penal concordado y comentado con jurisprudencia y leyes penales especiales y complementarias. LA LEY (Madrid, España), 2016.

${ }^{110} \mathrm{Si}$ bien es cierto que cumplirá con todos los requisitos del artículo 316 del CP con la única salvedad del elemento volitivo de la acción.

${ }^{111} \mathrm{Si}$ la conducta del empleador es la que ha supuesto que la persona trabajadora sufra el accidente no habrá duda sobre la responsabilidad del mismo, ahora bien, si la actuación de la persona trabajadora ha tenido algo que ver en el mismo habrá que determinar en qué grado es responsable el empleador o no.

${ }^{112}$ Es decir, establecer si las funciones que se están llevando a cabo suponen un riesgo en sí mismas debido al tipo de actividad al que están ligadas. Fundamentado en el Fundamento Jurídico 2 de la Sentencia 2/2014 de la AP de Albacete de 03 de enero de 2014.

${ }^{113}$ Entendiendo como base que la conducta del empleador es ejemplar y con la diligencia de un buen padre de familia.

${ }^{114}$ Fundamento Jurídico $3^{\circ}$ de la STS, Sala Segunda, de 29 de julio de 2002.

${ }^{115}$ Fundamento Jurídico $1^{\circ}$ de la STS, Sala Segunda, de 10 de abril de 2001.
} 
El derecho penal, pues, está persiguiendo el delito desde una doble vertiente: la creación del riesgo y el resultado indeseado. Es el artículo 318 el que clarifica quiénes son los responsables en caso de tratarse de personas jurídicas porque, obviamente, no pueden cumplir con las penas privativas de libertad; así pues, en estos casos, los responsables directos serán los administradores o encargados responsables de los mismos y, además, aquellos que conociendo la situación y pudiendo remediarla no hubiesen hecho nada al respecto $^{116}$. En este sentido, el Tribunal Supremo, en su Sentencia 121/2017, de 23 de febrero, estableció que los delitos contra las personas trabajadoras no forman parte de la lista taxativa del CP y, por tanto, no puede existir responsabilidad de la persona jurídica; ahora bien, sí de sus representantes legales o de los responsables en materia de PRL ${ }^{117}$, es decir, siempre existe responsabilidad penal recaída sobre una -o varias- persona física concreta.

En cuanto a la prescripción de estos delitos viene establecida en el artículo 133.1 del CP que establece que "Las penas impuestas por sentencia firme prescriben: A los 30 años, las de prisión por más de 20 años; a los 25 años, las de prisión de 15 o más años sin que excedan de 20; los 20, las de inhabilitación por más de 10 años y las de prisión por más de 10 y menos de 15; a los 15, las de inhabilitación por más de seis años y que no excedan de 10, y las de prisión por más de cinco años y que no excedan de 10; los 10, las restantes penas graves; a los cinco, las penas menos graves; al año, las penas leves" -de aplicación, con carácter general, a todos los delitos regulados en el CP-.

\section{La responsabilidad administrativa}

La responsabilidad administrativa del empleador en materia de PRL surge, directamente, de las acciones u omisiones que los empleadores han llevado a cabo y que se traducen, literalmente, en el incumplimiento de las normas vigentes en materia de PRL.

La responsabilidad administrativa en materia de PRL viene establecida, con carácter general, en el artículo 45 de la propia Ley con remisión al R.D. 707/2002, de 19 de julio, por el que se aprueba el Reglamento sobre el procedimiento administrativo especial de actuación de la Inspección de Trabajo y Seguridad Social y para la imposición de medidas correctoras de incumplimientos en materia de prevención de riesgos laborales en el ámbito de la Administración General del Estado.

Este tipo de responsabilidad se materializa en aplicación del sistema de sanciones previsto en el Real Decreto Legislativo 5/2000, de 4 de agosto, por el que se aprueba el texto refundido de la Ley sobre Infracciones en el Orden Social y que barema las mismas en:

\footnotetext{
116 Pudiendo, además, la autoridad judicial decretar alguna de las medidas previstas en el artículo 129 del CP: "La clausura temporal de los locales o establecimientos, la suspensión de las actividades sociales y la intervención judicial podrán ser acordadas también por el Juez Instructor como medida cautelar durante la instrucción de la causa...”.

${ }^{117}$ Es decir, el administrador de la sociedad o aquel que ostente el cargo de vigilancia y control de las personas trabajadoras será responsable directo del delito correspondiente -delito contra la seguridad de los trabajadores, lesiones o, en su caso, homicidio-, siempre y cuando haya habido una acción y omisión dolosa o imprudente por parte de dichas personas físicas.
} 
leves, graves o muy graves. Atendiendo a dicha baremación se establecerá la responsabilidad administrativa del empleador traducida en importe dinerario.

Para que, efectivamente, se materialice la responsabilidad administrativa -y en su caso la sanción correspondiente-, no es necesario que se haya producido un accidente o que una persona trabajadora haya sufrido un daño; el incumplimiento de cualquiera de los requerimientos legales en materia de PRL ya suponen la posibilidad de la imposición de la sanción correspondiente.

El primer artículo de la LISOS establece lo que se reconoce como infracción administrativa en el orden social como las acciones $u$ omisiones de los distintos sujetos responsables tipificadas y sancionadas tanto en esta como en cualquier otra norma del orden social y, además, establece su tipificación en leves, graves y muy graves en atención a la naturaleza del deber infringido y la entidad del derecho afectado. Atendiendo a estas notas características queda claro que cualquier infracción en materia de PRL queda amparada bajo el ámbito de la citada norma; además, esta misma en artículo 2 establece los sujetos responsables de las mismas estableciendo, en primer lugar, al empleador pero, además, otras como, por ejemplo, las empresas de formación o las auditoras -en nuestro caso en materia de PRL-.

Las infracciones administrativas en el orden social vienen establecidas en el artículo 1.1 de la LISOS, entendiendo como tales las acciones $u$ omisiones de los distintos sujetos responsables tipificadas y sancionadas En la presente Ley y en las leyes del orden social $^{118}$. En el caso de los accidentes de trabajo será responsable administrativamente el empleador -entre otros ${ }^{119}$-. Es el artículo 5.2 del anteriormente texto legislativo citado, además, el que regula que la infracción que dé lugar a la responsabilidad administrativa en materia de accidentes de trabajo debe estar prevista en la propia LISOS.

Es la propia LPRL la que regula la potestad de la Inspección de Trabajo y Seguridad Social para ejercer las funciones de vigilancia, control y sanción ${ }^{120}$ que no será únicamente multa pecuniaria sino que, además, podrán suspender la actividad o cerrar el centro de trabajo, paralizar los trabajos o limitar la facultad de contratación con la administración pública.

En el Capítulo II, Sección $2^{\text {a }}$ de la LISOS -artículos del 11 al $13^{121}$ - se establecen los baremos de sanciones aplicables en materia de PRL estableciendo la cuantía de las sanciones en el artículo 40.2 de la misma ${ }^{122}$; así pues las mismas pueden ir desde una multa de 40 a $2.045 €$ cuando sea de carácter leve, de 2.046 a 40.985 cuando sea de

\footnotetext{
${ }^{118}$ Recordemos que, una vez calificadas las sanciones deben graduarse según la gravedad de las mismas en leves, graves y muy graves lo que supondrá el tipo de sanción para cada una de ellas.

${ }^{119}$ Que vienen relacionados en el artículo 5.2 de la TRLISOS y, en referencia a la anterior, el artículo 13 en sus apartados undécimo, duodécimo y trigésimo.

${ }^{120}$ Fundamentándose en la LISOS.

${ }^{121}$ En ellos se establecen qué tipo de infracciones son de carácter leve, grave o muy grave.

${ }^{122}$ Tal y como establece la Disposición Adicional Primera de la LISOS: "La cuantía de las sanciones establecidas en el artículo 40 de la presente Ley podrá ser actualizada periódicamente por el Gobierno, a propuesta del Ministro de Trabajo y Asuntos Sociales, teniendo en cuenta la variación de los índices de precios al consumo".
} 
carácter grave y de 40.986 a $819.780 €$ cuando sea de carácter muy grave -todas ellas tienen grado mínimo, medio y máximo ${ }^{123}$.

La prescripción de las infracciones se establece en un año para las leves, en tres para las graves y en cinco para las muy graves -la fecha de inicio del cómputo para la prescripción fue la fecha en la que se produjo el hecho-, tal y como establece el artículo 4.3 de la LISOS.

En referencia a la reincidencia del empleador -regulada en el artículo 41 de la LISOShay que tener en cuenta que se entiende como tal cuando se cometa la misma infracción y que, además, suponga la misma calificación de otra que ya motivó una sanción en un plazo de 365 días siguientes a la notificación de la primera; además, si existe reincidencia la cuantía de las sanciones podrá incrementarse hasta el duplo del grado de la sanción correspondiente a la infracción cometida ${ }^{124}$.

\section{Los recargos en las prestaciones de la seguridad social}

El recargo en las prestaciones de la seguridad social no es un ente moderno sino que, por el contrario, ya aparecía regulado en la LAT de $1900^{125}$ y en su Reglamento de aplicación -actualmente regulado por el artículo 164.2 del TRLGSS- que pretende, sin lugar a dudas, prestar especial atención a los accidentes de trabajo y la responsabilidad de los sujetos implicados en los mismos -clara función de la acción protectora de la seguridad social-.

El recargo de las prestaciones de la seguridad social, además, no es incompatible con el resto de responsabilidades acaecidas tras el accidente de trabajo y así lo reconoce, además, el artículo 42.3 de la LPRL ${ }^{126}$.

La naturaleza jurídica del recargo en las prestaciones de la seguridad social se puede entender -y así lo hace parte de la doctrina- desde el punto de vista sancionador o punitivo del recargo si bien es cierto que esta cuestión es discutible ya que el incremento del recargo va directamente al patrimonio de la persona trabajadora que ha sufrido el accidente de trabajo y no al sistema de seguridad social; sin embargo existe otra parte de la doctrina que entiende que el recargo en las prestaciones de la seguridad social tienen un carácter indemnizatorio cuya finalidad es la de suplir o incrementar los ingresos de la persona trabajadora y que, por tanto, a mejorar el estado en el que queda la persona trabajadora -tesis por la que me decanto-; pero, desde luego, lo que está claro es que el artículo 164.2 del TRLGSS pretende evitar los comportamientos irregulares que puedan ser causa de accidentes de trabajo de las personas trabajadores endureciendo la

\footnotetext{
${ }^{123}$ En este caso he querido consignar, únicamente, los grados mínimo y máximo para cada una de ellas.

${ }^{124}$ Y podrá suponer, además, la paralización de los trabajos, la suspensión de los mismos, el cierre y la limitación para contratar con la administración pública.

${ }^{125}$ El artículo 5.5 de la LAT rezaba que "Las indemnizaciones determinadas por esta ley se aumentaran en una mitad más de su cuantía cuando el accidente se produzca en un establecimiento u obra cuyas maquinas o artefactos carezcan de los aparatos de precaución".

${ }^{126}$ Que establece que la responsabilidad administrativa será compatible con las indemnizaciones por danos y perjuicios y, además, con el sistema de recargo de prestaciones de la seguridad social $-\mathrm{y}$ así ha sido reconocido, además, en las SSTS de 2 de octubre de 2000, de 14 de febrero de 2001 y de 9 de octubre de 2001.
} 
repercusión de la acción u omisión del empleador y que debe cumplir tanto la función retributiva como la indemnizatoria.

Para que opere el recargo en las prestaciones de la seguridad social se hace necesario, a tenor del artículo 164.2 del TRLGSS, que se cumplan una serie de requisitos muy específicos: que se haya producido un accidente de trabajo -o enfermedad profesional en su caso-, falta de adopción de las medidas en materia de PRL previstas en la norma de aplicación, que exista causalidad entre el accidente y la falta de adopción de medidas en materia de PRL, que se haya producido un perjuicio, causado por el siniestro y que tenga derecho a una prestación de la seguridad social.

Este tipo de responsabilidad tiene naturaleza reparadora del daño, es decir, protege al trabajador que ha sufrido un accidentes de mayor forma que lo hace frente a cualquier otro pero, eso sí, imponiendo el coste añadido al empleador que ha incumplido con sus obligaciones en materia de PRL lo que supondrá que, este, soportará el incremento establecido legalmente; responsabilidad que tendrá carácter reparador pero, a su vez, con función preventiva indirecta por el efecto disuasorio que ejerce para con los empleadores ${ }^{127}$.

En lo que refiere al recargo de prestaciones de la seguridad social, tenemos que estar a lo dispuesto en el artículo 164.2 del TRLGSS que establece el pago, directamente, al empleador que haya incumplido lo instituido legalmente en materia de PRL señalando, además, la prohibición de asegurar dicha cobertura. La responsabilidad en materia de seguridad social se produce cuando como consecuencia de la falta de las medidas de seguridad necesarias se produzca un accidente de trabajo del que se deriven prestaciones de la seguridad social de cualquier ámbito -incapacidades, viudedad, orfandad, etcétera-. En este caso los beneficiarios tendrán derecho a un incremento de la prestación en un porcentaje que oscila entre el 30 y el $50 \%{ }^{128}$.

Este tipo de responsabilidad tiene una clara finalidad: que los empleadores cumplan con las obligaciones en materia de PRL y, por tanto, disminuir el número de accidentes que sufren las personas trabajadoras; tiene un componente sancionador imputable, directamente al patrimonio del empleador infractor, un componente indemnizatorio -ya que trata de compensar económicamente a la persona trabajadora aumentando la cantidad ordinaria que le correspondería- y, además, carácter prestacional -ya que funciona de igual manera que el resto de prestaciones de la seguridad social-. El beneficiario, lógicamente, será la propia persona trabajadora pero, además, será compatible con las indemnizaciones nacidas de la responsabilidad civil o penal ya que resarcen el daño desde distintas perspectivas.

El recargo en la prestación aparece cuando se dan una serie de características necesarias; es decir, tras el accidente debe reconocerse el derecho a la prestación económica de la

127 VALDEOLIVAS GARCÍA, Yolanda. El modelo de responsabilidad empresarial por incumplimiento de obligaciones de prevención de riesgos laborales. Op. Cit., p. 52.

${ }^{128}$ Dicho recargo correrá a cargo de la empresa. Para estos casos el empresario no podrá, en ningún caso, suscribir seguro de cobertura al estar explícitamente prohibido por la propia Ley. 
seguridad social -al trabajador o a sus beneficiarios en caso de fallecimiento de éste-, debe existir incumplimiento de la normativa en materia de PRL por parte del empleador y, además, debe probarse la relación causal entre el incumplimiento del empleador ${ }^{129}$ y el resultado de accidente lesivo que sufra la persona trabajadora.

Como ya observé, el porcentaje aplicable está establecido entre el 30 y el 50\%, ahora bien, no existe un baremo tasado para aplicarlo en cada caso por lo que se aplica en función de la tipificación de la infracción según la norma administrativa o, en su caso, por los órganos jurisdiccionales competentes.

El recargo en las prestaciones de la seguridad social -tal y como hemos visto en el apartado referente a la responsabilidad penal- no es susceptible de aseguramiento ya que dejaría de cumplir con uno de sus objetivos principales: el disuasorio y así lo ha establecido la jurisprudencia en diversas ocasiones.

El recargo en las prestaciones de la seguridad social suele establecerlo el Instituto Nacional de Seguridad Social -en adelante INSS- a tenor de lo establecido en el artículo 1.1.e del RD 1300/1995, de 21 de julio, sobre incapacidades laborales del sistema de seguridad social bien a instancia del beneficiario o tras actuar en el asunto la Inspección de Trabajo donde, además, deberá intervenir el Equipo de Valoración de Incapacidades y emitir informe al respecto.

Se debe aclarar que, además, en caso de que exista mejoría por parte de la persona trabajadora el recargo será revisables por lo que puede llegar a eliminarse incluso sin que se produzca el fallecimiento del perceptor de las prestaciones de la seguridad social correspondientes.

Es destacable que este tipo de recargo supone un aumento en la cuantía de la prestación y no una prestación en sí sometido al procedimiento recaudatorio del sistema de Seguridad Social convirtiéndose en un todo que conjuga prestación e indemnización ${ }^{130}$. Se puede entender, de forma clara, como una sanción para el empleador y una indemnización para la persona trabajadora.

\section{BIBLIOGRAFÍA}

ALARCÓN CARACUEL, Manuel. y GONZÁLEZ ORTEGA, Santiago. Compendio de seguridad social. Ed. Tecnos, 1991.

ALONSO OLEA, Manuel. Instituciones de seguridad social, Madrid, Civitas, $9^{a}$ Edición, 1983 , p. 22.

\footnotetext{
${ }^{129}$ No aplicará en caso de que intervenga un tercero ajeno a la empresa, exista imprudencia temeraria por parte del trabajador o exista causa de fuerza mayor.

${ }^{130}$ MONEREO PÉREZ, Jose Luis. El recargo por omisión de medidas preventivas". AA. VV., Tratado de Salud Laboral, vol. 1.
} 
BARRIONUEVO PEÑA, José. La responsabilidad empresarial por incumplimiento de las obligaciones de afiliación, alta y cotización a la Seguridad Social. Revista de Política Social, 1973, n 100, pp. 43-62.

DE LA VILLA GIL, Luis Enrique. La influencia de la Ley de Accidentes de Trabajo de 1900 en la construcción del ordenamiento laboral español. En Derecho del trabajo y seguridad social: cincuenta estudios del profesor Luis Enrique de la Villa Gil: Homenaje a sus 50 años de dedicación universitaria, 2006. pp. 103-142.

DESDENTADO BONETE, Aurelio. El recargo de prestaciones de la Seguridad Social y su aseguramiento. Contribución a un debate. Revista de derecho social, 2003, (21), 1128.

DATO IRADIER, Eduardo. Significado y representación de las leyes protectoras del trabajo. Revista general de legislación y jurisprudencia, 1909, vol. 57, nº 114, pp. 5-28.

DEL REY GUANTER, Salvador. el sistema de responsabilidades en materia de seguridad y salud laboral en el ordenamiento jurídico español: Carencias y propuestas de reforma. Boletín De Estudios Económicos, 2009, 64(196), 71.

DIEZ SCHWERTER, Jose Luis. Responsabilidad civil derivada de accidentes del trabajo y enfermedades profesionales: aspectos relevantes de su regulación y operatoria actual. Revista De Derecho, 2008, (31), 163.

FABREGAT MONFORT, Gemma. (2000). La responsabilidad empresarial en las contratas y subcontratas de propia actividad. Revista de treball, economia i societat, (17), pp. 23-35.

GARCÍA GONZÁLEZ, Guillermo. Los inicios de la previsión social en España: responsabilidad patronal y seguro de accidentes en la ley de accidentes del trabajo de 1900. Lex Social: Revista de Derechos Sociales, 5(2), 2015, pp. 1-32.

GARCÍA MURCIA, Joaquín. Responsabilidades y sanciones en materia de seguridad y salud en el trabajo. Aranzadi Editorial, 2000.

GARCÍA ORMAECHEA, Rafael., Jurisprudencia del Tribunal Supremo y de la Comisión Superior de Previsión sobre Accidentes de Trabajo: 1902-1934, Madrid, Suc. de M. Minuesa de los Ríos, 1935, pp.7-8.

GARCÍA OVIEDO, Carlos. Tratado elemental de derecho social. Sevilla, IGASA (2a Edición), 1946, pp. 331.

GARCÍA PADILLA, Margarita., Historia de la acción social: Seguridad Social y asistencia, en AA.VV., Historia de la acción social pública en España. Beneficencia y Previsión, Ministerio de Trabajo y Seguridad Social, Madrid, 1990, p. 408.

GÁZQUEZ SERRANO, Laura. Las nuevas tendencias jurisprudenciales en materia de responsabilidad civil del empresario. Madrid: Editorial Reus. 2012. 
GUERVOS MAILLO, María Ángeles. Los recargos tributarios autonómicos como instrumento de protección ambiental. Díkaion: revista de actualidad jurídica, 1996, no 5 , p. 8 .

MARAVALL CASESNOVES, Héctor. La Ley de Bases de la Seguridad Social y el Seguro de accidentes de trabajo. Revista de Política Social, 1964, nº 61.

MARTÍN VALVERDE, Antonio. La formación del derecho del trabajo en España. La legislación social en la historia de España, de la revolución liberal a 1936. Congreso de los Diputados, 1987.

MARTÍNEZ ABASCAL, Vicente Antonio y HERRERO MARTÍN, Jose Bernardo. Sistema de derecho de la protección social (3a. ed.). Tarragona: Publicacions Universitat Rovira i Virgili. 2016.

MONEREO PÉREZ, Jose Luis. El recargo por omisión de medidas preventivas. $A A$. $V V$., Tratado de Salud Laboral, vol. 1.

MONTOYA MELGAR, Alfredo. Sanción e indemnización: el recargo de las indemnizaciones por accidente de trabajo. Libro homenaje al Prof. Jiménez Fernández, 1967.

MUÑOZ MOLINA, Julia. El recargo de prestaciones en caso de accidentes de trabajo y enfermedades profesionales. Revista del Ministerio de Trabajo y Asuntos Sociales, 2005, (59), pp. 143-169.

MORALES GARCÍA, Oscar. Responsabilidad penal asociada a la siniestralidad laboral. XVI Jornadas Catalanas de Derecho Social: La responsabilidad laboral del empresario: siniestralidad laboral, 2005.

NAVARRO FERNANDEZ, Jose Antonio, y PERTÍÑEZ VÍLCHEZ, Francisco. Responsabilidad civil empresarial y riesgos laborales. Barcelona. Bosch, 2002, p. 22.

PÉREZ FERRER, Fátima. Cuestiones controvertidas sobre la protección penal de la seguridad e higiene en el trabajo. Cuadernos de política criminal, 2016, no 120, p. 137174.

PÉREZ MANZANO, Mercedes. El recargo de prestaciones sociales y la interdicción constitucional de doble sanción. In Protección penal de los derechos de los trabajadores: seguridad en el trabajo, tráfico ilegal de personas e inmigración clandestina, Edisofer, 2009, pp. 123-154..

PIC, Paul. Estudio crítico de la Ley de accidentes de trabajo francesa de 9 de abril de 1898: Estudio preliminar y traducción Icíar Alzaga Ruiz. Editorial Universitaria Ramón Areces, 2002.

PONS PONS, Jerònia. Las mutuas patronales y la gestión del seguro de accidentes de trabajo en España hasta su incorporación a la Seguridad Social (19020-1966). En El trabajo y sus riesgos en la época contemporánea: Conocimiento, codificación, 
intervención y gestión. Publicacions i Edicions de la Universitat de Barcelona, 2012. pp. 253-286.

RODRÍGUEZ-RAMOS LADARIA, Gabriel. Código Penal concordado y comentado con jurisprudencia y leyes penales especiales y complementarias. LA LEY (Madrid, España), 2016.

ROMERAL HERNÁNDEZ, Josefa. El recargo de prestaciones y la eficiencia del sistema de protección social. Nueva revista española de derecho del trabajo, 2018, no 211, p. 167-201.

SEMPERE NAVARRO, Antonio Vicente. Régimen jurídico de las mutuas patronales. Ed. Civitas, 1986.

SILVESTRE, Javier y PONS, Jerònia. El seguro de accidentes del trabajo, 1900-1935. En XVI Encuentro de Economía Pública: 5 y 6 de febrero de 2009: Palacio de Congresos de Granada. 2009. Pp. 123 y ss.

VALDEOLIVAS GARCÍA, Yolanda. El modelo de responsabilidad empresarial por incumplimiento de obligaciones de prevención de riesgos laborales. 2011. RJUAM, pp. 41-8. 